\title{
PROGRESS REPORT FOR THE STUDY OF MULTI-INSTITUTIONAL COLLABORATIONS IN HIGH-ENERGY PHYSICS
}

January 1989 Through March 1991

\section{DISCLAIMER}

\begin{abstract}
This report was prepared as an account of work sponsored by an agency of the United States Government. Neither the United States Gnvernment nor any agency thereof, nor any of their employees, makes any warranty, express or implied, or assumes any legal liability or responsibility for the accuracy, completeness, or usefulness of any information, apparatus, product, or process disclosed, or represents that its use would not infringe privately owned rights. Reference herein to any specific commercial product, process, or service by trade name, trademark, manufacturer, or otherwise does not necessarily constitute or imply its endorsement, recommendation, or favoring by the United States Government or any agency thereof. The views and opinions of authors expressed herein do not necessarily state or reflect those of the United States Government or any agency thereof.
\end{abstract}

Center for History of Physics A American Institute of Physics 
Progress Report for the Study of Multi-Institutional

Collaborations in High-Energy Physics

January 1989 through March 1991

I. Introduction: Purpose and Methodology of the Study. . . 1

II. Project Funding. . . . . . . . . . . . . . . . . . 3

III. Project Staffing . . . . . . . . . . . . . . . . . . 4

IV. Institutional contributions. . . . . . . . . . . . . . 4

v. Working Group and Advisory Committee . . . . . . . . . 5

VI. Census Development . . . . . . . . . . . . . . 7

VII. Program of Interviews for selected Experiments . . . . . 9

Selection of Experiments. . . . . . . . . . . . . 9

Selection of Individuals to be Interviewed. . . . . . 10

Preparation of Working Files. . . . . . . . . . . 10

Development of the Question Sets for Interviews . . . 11

Interviewing Activities on Selected Experiments . . . 11

Historical and Archival Analysis of Interviews. . . . 12

Sociological Analysis of Interviews . . . . . . . . 13

VIII.Probes of the Upsilon, J, Psi, and CESR/CLEO . . . . . . 14

Upsilon Discovery . . . . . . . . . . . . . . . . . 14

The J and Psi Discoveries . . . . . . . . . . . . 15

CLEO Collaboration at CESR Mini-Probe . . . . . . 16

IX. Study of subcontracting. . . . . . . . . . . . . . 16

x. Perspective Interviews . . . . . . . . . . . . . . 17

XI. Parallel Project Activities at CERN. . . . . . . . . . . 18

XII. Archival and Preservation Activities . . . . . . . . . 19

Archival Analysis . . . . . . . . . . . . . 20

Electronic Records. . . . . . . . . . . . . . 24

Survey of Spokespersons . . . . . . . . . . . 25

Appraisal Guidelines. . . . . . . . . . . . . . 25

site Visits to Accelerator Laboratories . . . . . . 26

XIII.Dissemination of Project Activities. . . . . . . . . . . 27

XIV. Activities for Balance of Grant. . . . . . . . . . . . . 28

XV. Final Reports. . . . . . . . . . . . . . . . . . 29

XVI. Other Products . . . . . . . . . . . . . . . . 30 
List of Appendixes:
A. Working Group for High-Energy Physics
B. Advisory Committee for High-Energy Physics
C. Question set for Senior Physicists
D. Historical and Archival Indexing Form
E. Archival Database Form
F. Preliminary Historical Analysis of Selected Experiments
G. Preliminary Report on the Upsilon Probe
H. Four Issues of the AIP Center Newsletter 
PROGRESS REPORT FOR THE STUDY OF MULTI-INSTITUTIONAL COIILABORATIONS IN HIGH-ENERGY PHYSICS

JANUARY 1989 THROUGH MARCH 1991

I. Introduction: Purpose and Methodology of the Study

Since World War II, the organizational framework for scientific research is increasingly the multi-institutional collaboration. However, this form of research has received only incidental attention from scholars. Without a dedicated effort to understand such collaborations, policy makers and administrators will continue to have only hearsay and their own memories to guide their management; even the records necessary for efficient administration, for historical study, and for posterity, will be largely scattered or destroyed.

The AIP Center, in keeping with its mission to secure the documentation of modern physics, seeks to redress this situation with a multi-stage investigation into areas of physics and allied sciences where multi-institutional collaborations are prominent. The goal of the study is to address the problems of documenting the history of these transient "institutions." In order to locate and preserve historical documentation, we must first understand the process of collaborative research and how the records are generated and used. Hence we are making a broad preliminary survey, the first of its kind, into the functioning of research collaborations involving three or more institutions.

our study is designed to identify patterns of collaborations, define the scope of the documentation problems, field-test possible solutions, recommend future actions, and build an archives of oral history interviews and other resources for scholarly use. Once the study is completed, the AIP center will make use of its findings to promote systems to document significant collaborative research.

We focus on major research "sites." In high-energy physics, sites are accelerator facilities. We collect three levels of descriptive data. At the most aggregated level, we prepare a 
census of collaborations by supplementing information that can be gleaned from on-line databases covering the science and technology literature. The census makes possible a quantitative analysis of basic collaboration patterns and their changes over time. At an intermediate level, we conduct interviews with 150180 selected members of collaborations chosen to cover a range of historical, sociological, and scientific parameters. Qualitative analysis of these interviews provides a foundation for generalizing on how scientists view the conditions of their fields and on where they think records of historical value repose. At the most detailed level, we conduct a few "probes" -case studies of very significant collaborations that seem certain to be of interest to future scholars. Probes make both for concrete experience in the collection of records and for historical monographs of publishable quality.

In addition, we give attention to industrial subcontracting because of the managerial problems this practice poses and the further dispersal of records it implies. We also conduct "special perspective interviews" with women and minority members of collaborations whose social roles merit study, and with others, such as managers of funding agencies and laboratory directors, who have information of value to our understanding of collaborative research.

Critical to the success of our study is the definition of categories for census data, the selection of collaborations for selective interviewing and probes, and the construction of interview question sets that are sufficiently varied to capture multiple perspectives on collaborations, yet sufficiently uniform to yield results to statistical and sociological as well as historical analysis. Our study of high-energy physics is guided by a Working Group of distinguished scientists and science administrators who have long worked in high-energy physics; historians who have studied this field; and archivists and sociologists of science. 
A number of products will result. Profiles written on multi-institutional collaborations will include analyses from several perspectives: the historical evolution of collaborations in high-energy physics during the 1970s and '80s; a discussion of the differences and similarities of the selected sites; a report. describing the sociological characteristics of the collaborations; a report on the role of subcontracting to industry; and an analysis of the documentation problems and opportunities encountered.

other resources developed by the project, including oral history recordings and transcripts, will be available at the AIP Center's Niels Bohr Library. In addition, we plan to microfilm a few selected sets of particularly valuable documentation; most, if not all, microfilming will be done after Phase I of the study. Finally, working in cooperation with institutional archivists, the project will locate and see to the preservation of records (in part, to field-test possible approaches and solutions). Indexed information on all these collections will be made widely known to scholars.

Key personnel include: principal investigator, Joan WarnowBlewett; associate investigator, spencer R. Weart; project historian, Joel Genuth; and project archivist, Lynn Maloney.

\section{Project Funding}

In addition to support for the project's domestic work from the Department of Energy (DoE), the National Science Foundation (NSF), and the National Historical Publications and Records Commission (NHPRC) at the National Archives, funding was received from the Melion Foundation to extend the study to take international considerations into account.

Melion support makes it possible for the AIP Center to include collaborations using the four American sites that involve teams (also referred to as groups) from outside the United states. In addition, the AIP center is able to enlarge its statistical census of all experiments conducted at selected sites 
to include experiments conducted at the European Laboratory for Particle Physics (CERN) in Geneva.

A separate Mellon grant to the CERN laboratory enables historian John Krige to carry out a coordinated, parallel study of experiments conducted at CERN. The methodology of the AIP project is fully employed in the CERN work.

\section{Project staffing}

Staffing was erratic during the first year, brought about by the resignations for personal reasons of the first project historian and project archivist. In each case, it took several months to locate and hire replacements and remaining staff were loaded down with carrying out essential project tasks.

In April 1990, project historian Nebeker announced he would resign his position in september to take on the position of associate historian for the IEEE Center for the History of Electrical Engineering. This advance notice enabled the AIP project to hire another postdoctoral historian of science, Joel Genuth, whose tenure overlaps Nebeker's. With the addition of project archivist Lynn Maloney to the staff in June 1990 and the employment of Genuth, we consider project staff to be complete and stable.

There has been only one change in project consultants. Sociology consultant Thomas Gieryn left in August 1990 because of the press of other commitments; since then the task of analyzing the project's interviews on selected experiments has been under the direction of Lynn zucker of UCLA.

\section{Institutional contributions}

The AIP contributed a major portion of the time of the Center's postdoctoral historian Finn Aaserud, particularly during 1989. It continues to support the project by contributing some time of the AIP librarian/archivist Bridget Sisk and the AIP Center's senior program coordinator Virginia French, as well as administrative and clerical costs. The AIP science writer 
Phillip Schewe has assisted the project by reading relevant articles and writing lay-language synopses of them as background material for project staff prior to the interviews. This has been very successful for our work, particularly since schewe is a former high-energy physicist.

The Stanford Linear Accelerator center (SLAC) too has made major contributions to the project by supporting the efforts of William Kirk, Louise Addis, and SLAC archivists, Roxanne Nilan and Robin Chandler. In addition to service on the project's Working Group, Kirk and Nilan conducted pilot interviews to test the project's questions set and, joined by Chandler, conducted 14 interviews related to the project's selected experiments. Addis (aiso on the Working Group) is providing critical leadership for the project's census work, as detailed below, and training project staff and consultants on the use of the SPIRES databases at SLAC.

The AIP project is also coordinating its work with a history project at FNAL, funded by the National Science Foundation and directed by historians of science Lillian Hoddeson and Catherine Westfall. The AIP project has shared its research results to avoid duplication of effort (such as interviewing physicists on the same experiments).

other contributions have been made by the laboratories, especially the support of the census work by the Brookhaven National Laboratory and the Fermi National Accelerator Laboratory, mentioned later in this report.

\section{Working Group and Advisory Committee}

The study of collaborations in high-energy physics has a Working Group and a larger Advisory Committee for Documenting Multi-Institutional Collaborations. Both groups include a number of experts (scientists, historians, archivists, and sociologists). However, the Working Group has a greater concentration of distinguished scientists and science administrators. The members of the Working Group for High-Energy Physics are 
listed in Appendix A. The project's Advisory Committee does not meet as a whole; its members have agreed to respond as individuals to our requests for advice. The Advisory Committee for High-Energy Physics is listed in Appendix B. Members of both the Working Groups and the Advisory Committee can be called on to author or co-author project reports and recommendations.

The project's Working Group for High-Energy Physics met twice: on 14-15 April 1989 and on 22-23 February 1991. The first meeting, near the outset of the project, was an effective tool for introducing the various groups to each others' interests and concerns. The physicists shared their knowledge of the process of collaboration from the perspective of funding agencies, laboratory administration, and laboratory users. These reports were enormously useful in shedding light on such critical points as how collaborations are formed and how they typically extend over a string of experiments. In addition, the archivists, historians, and sociologists expressed their concerns and interests as keepers and users of the records and eventual audience for the project's findings.

The products of this meeting included revisions to the project's draft set of questions for use in its interview program, the compilation of an initial list of experiments to be included in the interview program, and the selection of Upsilon experiments, besides the two already chosen (the $J$ and the Psi discoveries), for the more thorough "probe" study.

The purpose of the February 1991 meeting of the Working Group for High-Energy Physics was to review progress, critique preliminary findings, and set priorities for the rest of the study of multi-institutional collaborations in high-energy physics. All levels of project work were reviewed (the census; interviews of selected experiments; probe work; historical, sociological, and archival analysis; the parallel study underway of CERN experiments; and a study of subcontracting). In addition, the Working Group reviewed draft appraisal guidelines for records of high-energy physics experiments, plans for the 
project's final reports, and possible microfilming of selected files; finally, the Group discussed tactics the AIP center might use to identify key experiments from the past as well as in the future for special preservation efforts.

VI. Census Development

The broadest level of the study of multi-institutional collaborations in high-energy physics is the census of all highenergy physics experiments conducted for the period from 1973 through 1987 at the four American facilities and the CERN laboratory in Europe included in the study. This effort involved, first, defining basic data needed for the census, and second, learning how to manipulate the databases maintained for the highenergy physics community: the Experiments database by the Particle Data Group at the Lawrence Berkeley Laboratory and the HEP Publications database by SLAC and the DESY laboratory in Hamburg, West Germany. The Experiments database and the HEP publications database were made accessible to us through the SLAC Library.

For the most part, the strengths of the databases for project purposes were impressive. On the other hand, the databases had not been used previously for historical, sociological, or other "nonscientific" purposes, and certain weaknesses for project purposes were quickly apparent. These weaknesses range from the humorous and easily-solved (such as counting "et al" as a person in a collaboration) to the disappointing (e.g., periodic updating of the members of collaborations in the Experiments database removes the possibility of counting those on the original proposal and the identification of any previous spokespersons) .

on another level, not all laboratories were systematic in reporting which publications in the database were linked to specific experiments. This weakness was serious for a number of reasons; for example, it made it impossible to rank experiments in terms of numbers of publications and numbers of citations. For BNL, the most problematic case, project funds were used to 
employ as freelancer a recently retired BNL physicist, Robert Phillips, to begin to link BNL experiments to publications; this work has since been continued with BNL funding. In addition, FNAL agreed to make a special effort working directly with Louise Addis to complete its experiment-publications identifications. Finally, in enlarging the census to include the experiments carried out at CERN, we found another problem in the area: the linking of experiments with CERN report numbers rather than with journal publications.

At the time of this report very substantial progress has been made in linking publications to experiments. The work at FNAL is done, BNL's is nearing completion, and Addis is working with technical staff at CERN to resolve or simplify its problem. In addition, FNAL has agreed to add the task of linking instrumentation publications with experiments; since publications include engineers and some technicians, the FNAL effort will provide the AIP project with an additional glimpse of the "true" size of collaborations.

The work to complete the linking of publications with experiments will continue (essentially at no cost to the project) through the Spring of 1991. Its completion will make possible a measure of the productivity of collaborations in terms of numbers of publications and their citations. It will also permit the project to measure length of collaborations (from approval year to year of first major publication on experimental results). By the end of the project's study of high-energy physics, the HEP Publications database will be more useful than ever for both scientific and nonscientific queries.

Finally, the project has manipulated the SPIRES databases to compile three lists: (1) individuals most frequently involved in collaborations, (2) individuals serving as spokespersons on three or more collaborations, and (3) institutions most frequently involved. The project also plans to investigate the frequency of linkages of these key institutions. These data are particularly useful (when linked to other findings from the census, inter- 
views, and site visits) in pursuing the preservation goals of the study of high-energy physics.

\section{Program of Interviews for selected Experiments}

\section{selection of Experiments}

From the outset it has been clear ihat the project should look at a broad range of experiments in terms of physics and social factors. At the April 1989 meeting of the working Group, a number of criteria were agreed upon, divided into two types: sociological and scientific. From the sociological standpoint the set of selected experiments should cover a range in the size of the collaboration (both number of institutions and number of individuals), the starting year, the duration, the origin of the proposal, the success of the exp-iment, the site, and the subcontracting. From the scientific standpoint each of the following should be represented: the various detector types (including bubble chamber, hybrid emulsions, and calorimeter), a beam dump, a rare process, a "crucial test" of theory, a result contrary to current theory, a non-accelerator experiment, high transverse momentum, start-up of an instrument, start-up of an electronic facility, and a precision experiment. The working Group nominated a number of experiments. It recommended that the project request the three DoE sites to nominate additional experiments following the criteria set up by the Working Group. Such requests were made to heads of research programs of these laboratories through site visits, telephone calls, and correspondence in May 1989.

The project staff compiled a database containing information about all 72 experiments nominated for the project's program of interviews. For each experiment this included: title, participants, their affiliations, approval date, starting date, end date, and comments, classified as either physics comment.s or sociological/non-scientific comments. In July, consultants Galison and Gieryn met at the AIP with project staff to make the first cut in the list of experiments. From the original 72 
nominated by the Norking Group and by the representatives of SLAC, BNL, and FNAL, 27 experiments were selected, including all three CESR experiments. One of these CESR experiments was later selected for the final list in consultation with the laboratory director. Further cuts were planned in order to limit to twenty the number of experiments for the project's interview program.

During October and November 1989, the current whereabouts of spokespersons for all selected experiments were investigated. Letters to spokespersons were followed up by telephone calls. Through this process and subsequent discussion with advisors, a final list of 20 experiments was compiled. The list includes one non-accelerator experiment, the Irvine-Michigan-Brookhaven study of proton decay.

\section{selection of Individuals to be Interviewed}

The identification of individuals to be interviewed was made through discussions with the official spokespersons of the selected experiments (a first step made at the recommendation of project advisors) supplemented by conversations with other collaboration menbers. In all cases, the project sought to identify team leaders (typically called group leaders), women and minority members, and representatives of our various categories (postdocs, grad students, engineers, computer specialists, and technicians). A list of 179 candidates for interviews was thus compiled; a map was flagged with their locations to maximize travel efficiency.

\section{Preparation of Working Files}

Working files were developed for each selected collaboration, including a list of collaboration institutions and members, lay language summary of the experiment, selected publications, and -- where available -- a biographical entry for interview subjects and a bibliography of published results. An international map was flagged with locations of all interview subjects to maximize efficiency in travel plans. 


\section{Development of the Question sets for Interviews}

The project prop'ssal included a draft question set to be

used for the project's program of interviews. That draft (developed by project staff with consulting historian Peter Galison and sociologist Gieryn) was extremely useful in soliciting further suggestions and modifications. At the meeting of the working Group in April, and immediately thereafter, numerous additions and revisions were put forth by project advisors, s'caff, and William Aspray, Director of the IEEE Center for the History of Electrical Engineering.

In July 1989, three physics experiments (from 1974, 1975, and 1982) were selected for pilot interviews to test the question set. Project staff and consultant Gieryn conducted tesi isterviews with six individuals during september and october. The staff (along with Gieryn, Hargens, and Roxanne Nilan) met in October at Fermilab to discuss their experiences and modify the question set accordingly. The revised question set was then tested at SIAC by project advisors Nilan and Kirk during November. Only minor adjustments have been made since, and interviewers (and interviewees) agree the question set is highly successful in tracking the collaborative research process. A copy of the Question Set for Senior Physicists is in Appendix C. We also completed work on several additional shorter question sets for other members of collaborations: representative physicists who are graduate or postdoctoral students; women physicists; and representative non-physicists, including electrical engineers, computer scientists, and technicians. These question sets were tested and have been in use since the early months of 1990 .

\section{Interviewing Activities on selected Experiments}

From early January 1990 through March 1991, project staff have made 19 major field trips, in addition to those nearby. Each of these trips involved scheduling appointments with interviewees, completion of working files (lay language versions of 
key papers, etc.) and travel arrangements. In addition, appointments were made whenever possible with the archivists at each of the interviewee's institutions to discuss the project's documentation goals, the particular situation of the interviewee's files, and the current policies of the institutional archives. In addition to nine pilot interviews, 123 project interviews were conducted for the selected collaborations through March 1991.

Transcribing of the tape-recorded interviews, under the direction of the AIP Center's Virginia French, moved into high gear in spring 1990. Particularly taxing was the hiring of freelance transcribers with word processors to carry the large load of work. Duplicate tapes are shipped out and duplicate diskettes returned for inhouse printing. 110 interviews have been transcribed.

\section{Historical and Archival Analysis of Interviews}

Work was initiated in May 1990 on the historical and archival analysis of interviews for selected experiments. project staff developed a form covering historical themes and archival issues; this form is used to index interview transcripts. A second form is for an archival database to facilitate archival analysis. Both forms provide access points so that historical issues and archival issues can be tracked over time and by accelerator site. A copy of the indexing form is in Appendix D; the archival database form is in Appendix E. Thus far, 71 transcripts have been indexed. In addition, historical analysis of 65 transcripts and archival analysis of 48 transcripts was completed. An updated report on the historical analysis, distributed to the Working Group prior to its February 1991 meeting is in Appendix F; some results of the archival analysis are discussed in Archival and Preservation Activities, section XII below. 


\section{Sociological Analysis of Interviews}

The program to carry out sociological analysis of interviews was stalled until the appointment in August 1990 of Lynne Zucker, a professor of sociology at UCLA, for the position as consultant, replacing Gieryn. Zucker appointed a postdoc, Margaret Phillips, who started work in October under Zucker's supervision.

Zucker and Phillips have narrowed the theoretical sociological issues to be addressed and identified the kinds of variables to pursue those issues and the kinds of measures that can be used as surrogates for those issues. The issues to be pursued will include the persistence of affiliations and other team structure issues, influences on the degree of experimental innovation, the determinants of leadership, the effects of centralization of control, and sponsored mobility (especially the degree to which scientific research is carried out within an ever-narrowing network).

Zucker and Phillips are checking out the usefulness of alternative measures to supplement findings of the project interviews (such as the SPIRES databases at SLAC, citations including self-citations, and vitae) in order to identify the kinds of measures that can give the best accuracy in studying issues. The analysis will be multi-level: looking at individuals, home institutions, relationships of institutions to the experiment and to the accelerator site, experiments, collaborative teams, and the accelerator sites. Coding schemes have been finalized and the coding itself is underway.

Because of their late start, Zucker and Phillips will be pressed to complete the analysis of interviews and other data of experiments at American sites by mid-summer. In addition, if there is any available time, we would like zucker and phillips to analyze Krige's CERN interviews; this analysis would be supported by Mellon funds. 


\section{Probes of the Upsilon, $J$, PSi, and CESR/CLEO}

Project work on probes replicates to a large extent that of the planning and scheduling of interviews for the selected collaborations just described. However, the differences are marked. First of all, the probes involve talking to a large number of the participants. Second, probe work involves greater attention to collaboration records to determine what files should be saved, identify major gaps, and take steps necessary for preserving records of archival value at appropriate institutions.

\section{Upsilon Discovery}

our study of the Upsilon discovery at Fermilab, under the direction of former project historian Frederik Nebeker, covers a string of seven experiments conducted between 1970 and 1985 . Altogether, some 130 individuals and eight institutions (four of them outside the United States) were involved. Nebeker completed most of the interviewing and research work or the Upsilon probe during four major field trips before he left the project in midSeptember; other project staff have done Upsilon interviews as well. A total of 57 interviews (as well as notes of telephone discussions with four of the collaborators) were conducted. These include six spokespersons, 21 other senior physicists (including nine group leaders), postdocs, graduate students, engineers, and technicians.

Whenever Nebeker (or other staff) interviewed participants, he also examined and prepared rough inventories for experiment records. Nebeker also discussed Upsilon files with archivists at Fermilab, stony Brook, SLAC, CERN, and elsewhere to lay the groundwork for a plan to secure an adequate record of the experiments. Some steps have already been taken in conjunction with Adrienne Kolb, Fermilab archivist, to preserve certain very important materials, including detector logbonks and professional papers of two key participants. 
Nebeker's preliminary report on the Upsilon probe covering his work as of July 31 st is in Appendix G. His final report and a historical article on the Upsilon work are in preparation.

\section{The $J$ and Psi Discoveries}

Because of other commitments and because his wife was ill, consultant historian Peter Galison's work on the $J$ and Psi probes (with experiments corducted respectively at Brookhaven and SLAC) was seriously delayed until the Fall of 1990 .

Thus far, Galison has worked with archivists at SLAC to develop and carry out a survey mailing to all available participants of the Psi collaboration. A number of valuable records have been located, including unpublished internal technical memoranda (e.g., on event analysis, on the interface between equipment and computers, and others regarding the detector, storage ring, and accelerator), materials on Monce carlo simulations, and minutes of committees and subgroups. He has also compiled a list of key individuals to be interviewed on the Psi; interviews with three of these were conducted during March, the remaining are planned for the spring.

The participants of the $\mathrm{J}$ collaboration present more difficulties, since they are dispersed geographically. Perhaps a more important hurdle is obtaining a meeting with Samuel Ting, first for a review of his records (by Warnow-Blewett and MIT Archivist Helen Samuels) and later for an oral history interview by Galison. Once these are accomplished (we have hopes for May) interviews with other individuals on the $J$ team should follow shortly thereafter.

Because of the delays and difficulties, Galison will not complete his probe reports on the $J$ and PSI discoveries until August. 


\section{CLEO Collaboration at CESR Mini-probe}

The project has added a "mini-probe" to its list by upgrading the CLEO experiment at the CESR facility at Cornell University's Newman Laboratory from one of the 20 selected experiments. The reasons for this special attention are several: (1) Experiments are treated quite differently at CESR; only three experiments have been conducted since it began running in 1979 . CESR is one of the four main accelerator facilities in the U.S., but it is the only NSF-funded site; we want a better understanding of the differences between the NSF and DoE situations; (3) there has been little historical study of the cornell facility; we need to conduct some background research to piace the experiment in context; and (4) the project would benefit from another indepth exposure to research and preservation of archival records. The mini-probe is under the direction of project historian Joel Genuth.

In contrast to the J/Psi and Upsilon probes, which are organized around the examination of scientific discoveries, Genuth is examining CESR /CLEO from an institutional perspective. For example, he is looking for documents that shed light on Cornell's decision to pursue collider paysics and its efforts to attract the interest of the physics community and obtain funding from the federal government. Thus far, 15 interviews have been conducted and ten of these have been transcribed.

The archival aspects of the CESR/CLEO probe are particularly challenging, especially the records of CESR itself at cornell. Since CESR is a NSF-contract facility, it does not produce Federal records that fall under the domain of the National Archives. Warnow-Blewett and Genuth are trying to work out an arrangement with the corneli University Archives to safeguard the records of CESR and its experiments.

\section{Study of subcontracting}

One aspect of multi-institutional collaborations the AIP project has planned to explore from the outset is that of sub- 
contracting to industry. By means of project interviews and probes, we have sought to identify subcontracts the high-energy physics collaborations might have had with industry to carry out significant $R \& D$. We have not found subcontracts with design work or innovative engineering.

Nebeker, who is the consultant for the subcontracting study, presented this situation to the Working Group at its February 1991 meeting. There was general agreement that early contributions of industry to high-energy physics were done without contracts, although this is changing with the development of detectors for the SSC. During the period of the AIP study, there were a number of areas, such as super-conducting magnets and photcmultipliers, where the important R \& D was carried out within industry without subcontracts from high-energy physics experiments.

It was decided that Lecroy Electronics, a company that has for 25 years manufactured electronics exclusively for high-energy physics, will be the focus of the project's investigation of industrial research. Iecroy is important and a good example of successful interaction between industry and high-energy physics. Many of their staff are high-energy physicists and they have cultivated informal relations with the high-energy physics community as a way to learn their needs. Nebeker will make a site visit in May to Lecroy to interview key staff, review files, and discuss records-keeping practices.

\section{Perspective Interviews}

The Working Group, at its April 1989 meeting, recommended that the project conduct perspective interviews, outside of the selected experiments and probes, to supply missing pieces from the overview of community leaders, such as administrators at funding agencies and laboratories. Seven of these interviews have been completed (with Wallenmeyer and Hildebrand on DoE, Berley on NSF, Nishikawa and Kikuchi on KEK, MCDaniel on CESR, and Ticho on university-laboratory relationships). 
In June 1989, the AIP Advisory Committee for the History Center went further still and suggested the project interview a few women and minority physicists (in addition to those who participated in our selected experiments) who have made significant contributions to experimental high-energy physics or are articulate spokespersons for the concerns of women and minorities in the field. Five of these interviews with high-energy physicists (four women and one black) have been conducted.

Altogether 13 perspective interviews have been conducted; five of these have been transcribed. One or two additional perspective interviews are possible, if time permits.

IX. Parallel Project Activities at CERN

Historian John Krige is doing the study of selected experiments carried out at the European CERN laboratory in Geneva, funded by a separate Mellon Foundation grant. The methodology of the AIP project is fully employed in the CERN work, for example in the criteria for selecting experiments and the question sets used in interviews.

Work on the study at CERN got seriously underway towards the end of 1989, after meetings with individual physicists and the CERN Archive Advisory Committee. Five experiments were chosen to meet a range of different criteria in keeping with the AIP project: ( 1 and 2) UA1 and UA2, renowned for the discovery of the $\mathrm{W}$ and $\mathrm{Z}$ particles (large, colliders, electronic, historical importance); (3) the discovery of neutral currents (fixed target, bubble chamber, historical importance); (4) WA1 (large, electronic, neutrino physics, classical mid-1970s experiment, fixed target); and (5) WA9 (small, elegant, non-CERN participation, with an important soviet contingent).

Three lines of attack have been made on these experiments. First, about 20 of the scientists who participated in the collaborations have been interviewed to date, the sample deliberately chosen to include physicists, engineers, computer specialists, and some women. A perspective interview on the place of 
women in high-energy physics was also conducted. After some difficulty an excellent transcriber has been found and processing of the interviews is now proceeding rapidly. The findings confirm those made on experiments at American sites.

Second, a catalog of the collections of papers of two physicists involved in two of these experiments (JA1 and neutral currents) has been made. The first is particularly comprehensive and can serve as a valuable guide for archivists and historians to the kind of material that is generated in a large collaboration. In addition, Krige has identified other important papers and encouraged physicists to deposit them in appropriate repositories; this work has been supported by the CERN Archive Advisory Committee with several collections going to the CERN Archive.

Third, some results of Krige's work have been used in a CERN Internal Report on the relation between CERN and its user community; a more extensive paper is in preparation. Some data are also being used to compare the CDP at FNAL with the UAl, where Krige is cooperating with a young American graduate student.

\section{Archival and Preservation Activities}

There are a number of ways the project is taking steps during the two-year study of high-energy physics to have an impact on the records-keeping practices of archivists and scientists. From the start, for example, our interviews with scientists have been conducted at their home institutions so that we can review their files and also meet with the institutional archivists to talk about project goals and their current archival programs. These meetings with scientists are, virtually without exception, the first time anyone has discussed with them the potential historical value of their papers. The meetings with archivists strengthen the AIP Center's cooperative ties, give us "grass roots" information on the likelihood of saving records of 
multi-institutional collaborative research, and in return let us give information and encouragement.

\section{Archival Analysis}

Based on the interviews conducted thus far for our selected collaborations and probes, sice visits, reviews of records, and discussions with archivists, a pattern of records creation and retention is beginning to emerge. We have some confidence in these findings. For one thing, our interviews have deliberately covered a range of positions: spokespersons, additional senior physicists (including group leaders), postdoctoral research assistants, graduate students, engineers, and technicians. In addition, the multi-institutional collaborations selected for study have covered the ranges of size, types of research, national and international membership, and approval years for the period of study (from 1973 through 1984).

More general findings of our archival analysis indicate that physicists keep material from experiments they enjoyed even if those materials do not remain useful to them; unfortunately, they often do not know where those materials are. Documentation from user-dominated collaborations tends to be more sparse than from collaborations with strong accelerator laboratory groups. Internal memos, e-mail, and transparencies most often exist, although internal memos are rarely generated by collaborations with less than four insicitutions and fewer than 25 people. Half the interviewees keep e-mail with two-thirds of those that keep it printing the e-mail out; all prune e-mail to weed out the trivial. Transparencies are rich in information and are passed around the collaboration to help others prepare talks. The more recent the experiment, the more voluminous the records. One overall conclusion is that the role of the accelerator facility and the role of the spokesperson for the collaboration, point to the two most promising locations of papers.

The AIP Center knew from its earlier study of DoE National Laboratories that the laboratories are the best source of docu- 
mentation on the activities of their Program Adrisory Committees (especially, applications from collaborations for experimental work and accelerator beam time). Our current work provides evidence for other significant documentation of collaborative work at the laboratories. In particular, we see the emergence of more formal contracts covering the responsibilities for the entire effort (detector development and construction, (omputer facilities, and the like) assigned both to the laboratory and to each of the institutional members of collaborations. In addition, our interviews show that the laboratories provide storage facilities for much experimental data (perhaps because of good storage conditions for magnetic tajes) and, at least sometimes, for detector logbooks and engineering drawings. Finally, there are some indications of shifts from academic laboratories to accelerator facilities for fabrication of detector components.

The role of the spokesperson provides the other most promising source of documentation. This role appears to be changing in character. Its original purpose was to provide the accelerator laboratory with a single contact person for the collaboration. With larger numbers of people and institutional members, the role of spokesperson has come to encompass managerial tasks on behalf of the collaboration itself. There is, for example, ample evidence of collaboration-wide mailings that may correlate nicely with the larger, more recent collaborations; responsibility for such mailings appears to fall to spokespersons. In the best cases we've seen, these "archives" are well-organized and cover all aspects of the collaboration's work, including minutes of collaboration meetings -- with technical reports from group leaders and others on their assignments for detector development and data analysis -- technical memoranda, and other intra-collaboration mailings. In other cases, spokespersons appear to have kept many of these files but they are literally in piles all over their offices and may be difficult to extract from other, unrelated materials. Unfortunately, there is greater evidence of collaborations for which communication is far less formal, 
perhaps centered around meetings and phone calls, resulting in far thinner documentation. One final point of potential concern regarding the role of spokespersons is the apparent tendency toward rotation of spokespersons and toward co-spokespersons. This may be related bot $n$ to the increasing administrative responsibilities and to the geographical spread of institutions involved.

At the level of institutional teams, records creation centers on their assigned responsibilities for detector components and data analysis. It is by no means clear that such detailed technical records merit permanent retention, particularly out of context with other collaboration documentation. We will have to evaluate these records along with other, more compact documentation such as Ph.D. theses and summary technical reports. We will also have to continue tracking the record-keeping habits of individuals (many of whom toss files they see no further use for) and the likelihood of documenting group level work through the institutional setting.

Institutional archival policies are obviously key to the preservation of documentation. Our census shows that the two dominant settings for American members of high-energy physics collaborations are academia and Federally-Funded Research and Development Centers (FFRDCs), primarily DoE national laboratories in the case of high-energy physics. On the academic side there is a long-standing tradition of documenting full careers of outstanding faculty. But will academic archivists be receptive to the idea of documenting their share of outstanding multiinstitutional collaborations? Our discussions about the project with academic archivists indicate a wide interest in the archival issues involved. At the same time, in terms of programs their particular archives are interested in (and feel able to do something about), academic archivists often give us an "it all depends" response. The greatest hesitancy relates to records of group leaders and technical files of in-house laboratory work. These discussions and the AIP's previous experience with academic 
archives lead us to believe we will have the greatest success where the aims of documenting collaborations overlap with the aims of documenting significant careers. Faculty members who have served as spokesperson on one or more collaborations or, perhaps, as group leader on a number of collaborations will be more likely to have their papers preserved in academic archives. on the FFRDC side, there is some recent evidence of improvements in care of papers in general -- at least for short-term retention. This may be due to more office space and the existence of records management programs. Also working on behalf of documenting collaborations is the tradition of organizing files along project lines, a tradition strengthened by ever more formal requirements for budget requests at these laboratories. However, archival programs are recent (the earliest go back to the late 1970s), not always fully operational or professional, and in some cases (notably Brookhaven) barely more than an affectionate term for a few records. One set of issues, then, relates to the extent to which laboratory archival programs can secure valuable files documenting experiments conducted at their sites. A second set of issues relates to files at one FFRDC documenting experiments conducted at another FFRDC. In this regard we are particularly concerned about the security of records of spokespersons. will the laboratories consider such files outside their domain of responsibility if the experiments in question were conducted at other facilities? We will follow up on these issues during the remainder of our study.

overall, the methodology has been thoroughly effective in identifying the archival issues and pointing the way toward preservation. As expected, the in-depth work on the selected probes is proving to be particularly valuable in issues regarding appraisal of technical documentation; we also expect probe work to be useful in identifying specific difficulties in saving the records. We are more surprised at how valuable the analyses of the interviews covering selected collaborations can be in combination with the census work. The historical analysis and the 
archival analysis provide both an overall understanding and specific information on records creation and retention of records by the various collaboration members. The census combines well with these findings by giving us names of key institutional and individual players that we can approach for practical preservation work.

\section{Electronic Records}

Because of their increasing role in science, the project is tracking the creation, use, and retention of electronic records by covering a variety of issues in the project's question set used in all interviews. For example, questions regarding modes of communication between groups in a collaboration show (in addition to some traditional correspondence) a dramatic shift from long distance telephone to fax and electronic mail in the late 1970s. Patterns of retention (paper printout, selective or full retention on hard disk, and destruction) vary from person to person. Overall, we see the impact of fax and electronic mail on documenting the collaborative process as a positive one; after a long stretch of telephone communication, scientists are back to creating more records.

The role of computer technology in the research process is another focus of our question set. One preliminary finding is that, although software programs are increasingly available from laboratory libraries and other sources, each collaboration must create at least some aspects of the software to address specific research topics. There is evidence of logbooks and other records to document programming activities; it is not yet clear when such recorts-keeping practices began, how widespread they are, or the extent to which such records have been retained.

The most important finding ir the area of electronic records relates to the long-term usefulness of electronic research data. (Since the demise of butble chambers in the 1970s, virtually all research data in high-energy physics is in electronic format.) In answer to our question, all interview subjects thus far agree 
that raw data tapes would not be useful to those outside the collaboration; this applies to future high-energy physicists as well as to historians and other researchers. The potential usefulness of summary data tapes to outsiders is far higher, although there is insufficient evidence thus far to justify archival retention of more than a small sample.

We realize that these findings regarding electronic research data have enormous archival implications in documenting highenergy physics.

\section{survey of spokespersons}

The AIP project is in the middle of a survey of physicists who have served three or more times as spokesperson (principal investigator) for multi-institutional collaborations in highenergy physics. Our interviews indicate that, as collaborations have become larger and more bureaucratic, spokespersons have taken on more managerial responsibilities including records distribution. Our findings will provide details on patterns of records retention by spokespersons. When we locate collections of archival value, we will contact the institutional archivists so that steps toward preservation can begin at once. (Work on a particular case is often the best way to "sell" a practice in general.) The survey will be completed in the spring of 1991.

\section{Appraisal Guidelines}

Warnow-Blewett prepared a draft "Appraisal Guidelines for Records of High-Energy Physics Experiments" prior to the February 1991 meeting of the Working Group for the purpose of obtaining comments on: (1) what records should be kept for all experiments and (2) what additional records should be kept for "significant" experiments.

At that meeting a consensus formed around keeping the following records for all experiments (in addition to published materials) :

(a) Physics Advisory Committees records 
(b) Laboratory Directors' files (typically the director for high-energy physics)

(c) Proposals

(d) Memoranda of Understanding (contracts)

(e) Blueprints of detectors and their components

(f) Progress reports to funding agencies (both narrative and financial)

(g) Annual budget statement developed by the DoE laboratories of experiments to be done (Work Package and Field Task Authorization Proposal [WPAS]).

It was noted that records in categories (a) through (e) are already retained by the DoE accelerator laboratories; the AIP project is in the process of checking this out. It seems likely that both NSF and DoE have retained progress reports (category f); the AIP needs to check into this and to also see if noncurrent files could be transferred to the National Archives. Finally, the WPAS (category $g$ ) were viewed as extremely valuable files; even though they do not pertain to all our experiments, the project should investigate if the labs or DoE headquarters save them.

The identification of additional records to be kept for a highly selected number of experiments was also discussed by the Working Group, but not finalized. It was decided that warnowBlewett should send Galison revised appraisal guidelines and have him point out files that he, as our chief consulting Historian, would like to see saved for significant experiments. This listing will then be shared with the Working Group so that individuals could, e.g., state that certain types of records should be saved for all, not just exceptional, experiments.

\section{site Visits to Accelerator Laboratories}

Site visits to the five laboratories under study have been particularly important in two phases of project work. First, near the outset of the project, when laboratory staff were generous in providing detailed tours of their facilities, includ- 
ing discussions with collaboration members in the midst of conducting experiments. Such tours were essential to our understanding of the process of collaborations in high-energy physics. The scheduling of these site visits were coordinated with periodic meetings of staff, consultants and advisors. Particularly important were three site visits (in october 1989 and January and July 1990) to the CERN laboratory in Geneva to coordinate project work with CERN historian John Krige.

The second period of site visits to the accelerator laboratories is currently underway for the purpose of determining the extent to which the laboratories retain records documenting collaborative research and to obtain current information on their general records retention policies and archival programs. our meetings are with top-level science administrators as well as with those in direct charge of records.

\section{XIII.Dissemination of Project Activities}

The May 1988, May 1989, Fall 1989, and Fall 1990 issues of the AIP Center for History of Physics Newsletter had lead articles reporting on project activities. The Fall 1990 issue also featured a summary of preliminary findings (pages 4-5). Copies of these issues are in Appendix $\mathrm{H}$.

Warnow-Blewett and Nebeker spoke about the project at the Annual Meeting of the Society of American Archivists held in St. Louis, Missouri, in october 1989. Warnow-Blewett also spoke on documentation strategies and archival research (focussing on the AIP Center's study of multi-institutional collaborations) at a conference convened in May 1990 by the Beckman Center for the History of Chemistry and another conference in December 1990 convened by Georgetown University. Future papers will be given by Warnow-Blewett in June 1991 in Milan, Italy, at a conference on archives for history of science and technology and at the Annual Meeting of the Society of American Archivists in September 1991. Formal publications on the project by Warnow-Blewett are planned for 1991 issues of American Archivist and osiris. 
XIV. Activities During the Balance of the Grant Period

A cost extension for the project was approved by the DoE. These funds will support the time of project historian Joel Genuth and project archivist through August 1991 and help support the publication of the project's final reports.

Based on this additional support, the schedule for the remaining months of the grant is as follows.

(a) By 1 June:

Travel for interviewing by Genuth, Maloney, and WarnowBlewett, is completed.

Galison completes detailed outline of probe reports on the $\mathrm{J} / \mathrm{Psi}$ discoveries (he continues interviewing through July).

(b) By 1 July:

Indexing for historical and archival themes of interviews of selected experiments completed.

(c) By 15 July:

Nebeker completes probe report on the Upsilon discovery. Genuth completes draft of mini-probe report on the CLEO collaboration and CESR.

Survey of spokespersons and database on archival findings completed by Maloney.

Appraisal Guidelines for Records of High-Energy Physics is completed by Warnow-Blewett.

Census database is completed at SLAC; manipulation for census report begins.

Krije submits descriptions of selected files documenting experiments at CERN.

\section{(d) By 1 August:}

Draft archival analysis by Maloney and Warnow-Blewett completed.

Catalog listing of selected files completed by AIP librarian/archivist Bridget sisk.

Review of candidates for microfilming done by WarnowBlewett.

Nebeker completes report on subcontracting (Lecroy Electronics). 
(e) By 15 August:

Galison completes final probe reports on the J/Psi discoveries.

Zucker and Phillips complete analysis of interview transcripts and submit final report.

Genuth completes historical analysis of interviews of experiments using American sites.

Krige completes historical analysis of interviews on CERN experiments.

Census report completed by Addis, Hargens, and Maloney.

\section{(f) BY 1 september:}

Genuth completes interweaving of Krige's historical analysis with his own.

All final reports assembled under Warnow-Blewett's direction.

Printing and distribution of reports will follow, coinciding with the 1 september beginning of the AIP project's Phase II: The study of collaborations in space science and Geophysics.

\section{Final Reports}

There will be three final reports on high-energy physics collaborations:

(a) The first report will cover in detail the historical and sociological analysis and include a summary of archival findings and recommendations (ca. $120 \mathrm{pp}$; ca. 200 copies). The contents will include: report on analysis of census work; historical analysis of selected experiments at the four American sites and CERN; sociological analysis of selected experiments at the four American sites; probe reports on the Upsilon, $J$, and Psi discoveries and on the CLEO collaboration and CESR facility; report on subcontracting and Lecroy Electronics; and a summary of the project's archival findings and recommendations.

(b) The second report will detail archival findings and include a summary of historical and sociological analysis (ca. 80 
(b) The second report will detail archival findings and include a summary of historical and sociological analysis (ca. 80 pp.; ca. 150 copies). The contents will the project's archival analysis of interviews, census, and surveys; guidelines for appraisal of records of high-energy physics experiments; a listing of key papers located; project recommendations; and a summary of historical and sociological analysis.

(c) The last will be a summary report covering all project findings and recommendations for widest distribution (ca. 30 pp; 300 coppies or more).

\section{Other Products}

Scholarly papers will be submitted to history of science and sociological journals. These will include papers by: Nebeker on the Upsilon experiments, Genuth on the CLEO collaboration in the institutional setting of the CESR facility, Galison on the J/Psi discoveries, Zucker and Phillips on sociological aspects of highenergy physics collaborations, and two papers by Krige, one on the relation between CERN and its user community and the second a comparison of the CDP at FNAL with the UA1 in which Krige is cooperating with a young American graduate student.

Project records, especially interview tapes and transcripts, will be preserved in the AIP Center's Niels Bohr Library for historical and other research purposes. In addition, the project will microfilm selected paper files of high historical value although most, if not all, of this microfilming will be carried out during the next phase of the project; the microfilms will be held at the AIP and at other repositories interested in obtaining copies. Finally, the project is taking steps to preserve records of archival value at appropriate repositories and research laboratories; such actions focus on saving records documenting our indepth case studies (the "probes"), but also include followups when opportunities arise from any project activities, such as the survey of spokespersons. 
efforts, both at SLAC and at CERN, to take steps to identify outstanding experiments and secure their documentation in laboratory archives.

The work to document high-energy physics will continue at the AIP Center long after this study is completed. Among other activities, the center will develop a mechanism to identify major high-energy experiments from the past as well as those in the future. This will involve participation of laboratory directors, the NSF and DOE program officers, the AIP Public Information Division and Physics Today staff, members of the National Academy of Sciences review panels, and the use of sociological data and criteria to select experiments that seem significant or controversial and, perhaps, some that seem typical. once experiments have been selected, the AIP Center would work with institutional archivists and records managers to secure the historically valuable files.

Joan Warnow-Blewett

16 April 1991 
AIP Working Group for Documenting Multi-Institutional

Collaborations in High-Energy Physics

\section{Main Consultants:}

(History)

Prof. Peter Galison

Stanford University

(Archives)

Ms. Roxanne Nilan

Stanford Linear Accelerator center

(Sociology)

Prof. Lynn Zucker

University of California

at Los Angeles

Prof. Lowell Hargens

University of Illinois

Archival Representatives:

(Academic)

Ms. Helen Samuels

Massachusetts Institute of Technology

(Corporate)

Ms. Anne Millbrooke

United Technologies corp.

(Federal)

Dr. Sharon Gibbs Thibodeau National Archives and

Records Administration

(Federally-Funded Research and Development Centers) Ms. Victoria Davis

Fermi National Accelerator Laboratory others on Working Group:

Ms. Louise Addis

Library

Stanford Linear Accelerator Center

Dr. David Berley

Physics Program

National Science Foundation

Prof. Sheldon Glashow

Lyman Laboratory

Harvard University

Dr. Bernard Hildebrand

Div. of High Energy Physics Department of Energy (Retired)

Mr. Herbert Kinney

Office of the Director

Brookhaven National

Laboratory

Mr. William Kirk

Office of the Director

Stanford Linear Accelerator Center

Prof. Ronald Kline

Department of Electrical

Engineering

Cornell University

Dr. Derek Lowenstein

AGS Department

Brookhaven National

Laboratory 
Dr. Robert Smith

National Air \& Space Museum and

Department of History and Philosophy of Science

The Johns Hopkins University

Dr. William Wallenmeyer

Southeastern Universities Research Association

Prof. Robert R. Wilson

F. R. Newman Laboratory of Nuclear studies

Cornell University

Dr. Stanley G. Wojcicki

Experimental Group $G$

Stanford Linear Accelerator Center

Prof. Harriet Zuckerman

Department of Sociology

Columbia University

\section{AIP Project staff}

Ms. Joan Warnow-Blewett

Project Director

Dr. Spencer R. Weart,

Associate Project

Director and Chair, Working Group

Dr. Joel Genuth

Project Historian

Ms. Lynn Maloney

Project Archivist 


\section{APPENDIX B}

AIP Advisory Committee for Documenting Multi-Institutional

\section{Collaborations in High-Energy Physics}

Prof. Ronald Breiger Department of Sociology Cornell University

Prof. David Edge Science Studies Unit University of Edinburgh

Dr. Lillian Hoddeson Department of Physics University of Illinois

Prof. Robert Kargon Department of History and Philosophy of Science The Johns Hopkins University

Dr. Henry Lowood

Head Librarian, Physics Library

Stanford University

Dr. Allan Needell

Department of Space History National Air \& Space Museum

Dr. Robert seidel

Bradbury Science Museum Los Alamos National Laboratory
Prof. Silvan S. Schweber

Department of Physics

Brandeis University

Prof. Herbert Smith Department of Sociology University of Pennsyl.vania

Prof. Sharon Traweek

Department of Anthropology

Rice University

Dr. Catherine Westfall

History office

Fermi National Accelerator Laboratory 


\section{APPENDIX C \\ QUESTION SET FOR SENIOR PHYSICISTS \\ Revised March 1991}

[Lead-in:]

I'd like to ask you about Experiment began in 19

at

$[l a b]$, which

Here are a lise of some of the participants and a list of some of the publications reporting results of the experiment.

Our Project is archival as well as historical, so I'll be asking some questions about the availability of documents or other materials that might be of use to future historians of science. There will also be questions about the social organization of the experiment, the physics produced, and the equipment involved.

First, some questions about yourself:

(1) You got your Ph.D. at University in 19 . What was the title of your dissertation? Who was your dissertation advisor?

Did you have other mentors?

(2) Did your affiliation change during, or since, the experiment?

a) If so, did you bring papers with you when you moved?

(3) Do you write letters to colleagues?

a) Do you often annotate preprints?

b) Do you have a note-taking routine? For example, do you keep a telephone log? Do you take notes during formal or informal conferences? Do you make notes to a file (perhaps electronically)?

c) Do you save e-mail? In hard or soft format?

(4) How are your files organized?

a) Do you keep your files on this experiment separate from other files?

b) Where are they kept? 
c) Do you have another office?

d) Do you use storage at home, on campus, or at a laboratory?

Let's talk about the formation of the team:

(5) Was the team that worked on Experiment a collaboration formed to work on earlier experiments?

IF "YES", ASK QUESTIONS 4 AND 5 ABOUT THE HEAD OF THE CHAIN AND ASK ALSO QUESTION 6.

IF "NO", ASK QUESTIONS 4 AND 5 ABOUT THIS EXPERIMENT AND SKIP QUESTION 6 .

(6) How and when was the team that worked on this experiment formed? How and when was the spokesperson selected? ASK OF THE SPOKESPERSON: What were your responsibilities as spokesperson?

(a) Was there an original "core" set of members?

(b) How was each institutional team added? In what order? How were those decisions made?

(c) Did you have any previous personal or institutional links to the other collaborators?

(7) What factors were important in deciding who would be part of the team (access to money, specialized physical or technical knowledge, access to specialized equipment, mentor-student linkages, congeniality, etc.)?

(a) Do you know if any individuals or institutions were included in order to score "political" points?

(b) Did your team have theorists on board? Were they formal members of the team or informal advisors? How did they influence the experiment?

ASK ONLY IF THIS EXPERIMENT WAS NOT AT HEAD OF CHAIN (8) What were the significant changes in membership of the collaboration in the experiments leading up to Experiment ?

(a) What caused those changes in personnel? 
(9) Were any individuals or institutional groups considered as collaborators, but did not end up on this project? Why?

(a) Were these groups eventually not asked to join, or did they decline the invitation?

(10) After this experiment ended, did some members of the collaboration continue to work together?

Now some questions about the proposal:

(11) Were you involved in writing the proposal?

IF "YES", ASK QUESTIONS 12 AND 13

IF "NO", SKIP TO QUESTION 14

(12) What inspired the proposal for this experiment?

(a) Was the proposal a response to a new research opportunity, like the availability of some new accelerator or other instrument, or to some recent discovery or theory?

(b) Who were the principal contributors to the idea for this experiment?

(c) What previous research materials did you use to prepare for this experiment (e.g., articles, records, log books)? During the course of the experiment did you consult any of them?

(13) What was the sequence in securing the funding for the experiment? Were there disputes?

(a) What kind of support came from each source? (to the university departmental program? to the collaboration from the lab or from other sources?)

(14) Tell me something about the team's relationship to [lab]: Who made the presentation(s) to the Physics Advisory Committee at the lab? Was there a contract with the laboratory? Can you say something about interactions with the Committee? Did the lab place conditions on approval if the proposal?

(a) Tell me something about the team's relationship to the funding agency: how were contacts made? Did the agency place conditions on approving funds for the research? 
(b) Were you involved in writing reports to the funding agency? Did you assemble files to assist in this process?

Let's turr, to some questions about the equipment and software used in this experiment:

(15) First of all, how did groups communicate during this phase?

a) Were minutes taken? If so, were they systematically distributed?

(16) How was responsibili y for making major pieces of equipment assigned? Were tiere any disputes?

a) Did the detector differ either quantitatively or qualitatively from that originally proposed? If yes:

What was the idea?

How did it come up?

Whose idea was it?

Did pursuing the new idea require changes in asisignments in work?

(17) Tell me about the piece of equipment or software that you were most involved with.

(a) Was this equipment already available--either at the accelerator or at one of the participating institutions--or did it need to be built more or less from scratch?

(b) Was there a strong infrastructure at the university -inhouse lab facilities and access to engineers and technicians -- for building components or prototypes?

(18) Were there subcontracts involved in which a company or individuals from outside of the collaboration played a role in helping design an important piece of equipment? IF "YES", ASK: Who would know most about these?

i19) How did the groups communicate while you were building equipment at separate institutions (collab meetings, other trips, phone calls, letters, e-mail)?

(20) Who was mainly responsible for the assembly of the equipment at $[l a b]$ ? How cid that go? WHEN RELEVANT, ASK: Why was no laboratory person listed as collaborator? 
Now some questions about testing and data runs:

(21) How long was the period for equipment testing and break-in and other such preparations at the accelerator laboratory?

(22) Did any large changes have to be made in the equipment? What was the decision-making process for these changes?

(23) Did you experience major delays (caused, for example, by accelerator-beam problems or detector breakdown)? Were there communication or decision-making problems?

(a) What happened during "downtime"?

(24) Over what time period did the principal data runs take place?

(25) What was the division of labor during the run? Who did what, and how were such assignments made?

(a) Who was present at the data runs of the experiment (senior staff, junior staff, grad students, post docs, engineers, technicians, computer specialists, accelerator staff, etc.)?

Let's talk about the analysis of data after the runs:

(26) What sort of data analysis did you do? What analysis was done at the other institutions involved in the experiment?

a) Which people or groups became especially important during this phase? What role did theorists play in this stage?

b) Was the data analysis mostly done at the lab or was significant work done on campus? Was that a matter of choice?

(27) How did groups communicate during the data-analysis phase? Did the collaboration meet as frequently as before?

a) Were minutes taken? If so, were they systematically

distributed?

b) Do minutes include transparencies?

c) Were there any particularly good note-takers? 
(28) Was the data analysis ever contested within the team? By outsiders? IF YES, ASK: What was the point of dispute? How was the dispute resolved?

a) Did anyone come up with new techniques that improved the date analysis? If yes:

What was the idea?

How did it come up?

Whose idea was it?

Did pursuing the idea require changes in assignments of work?

(29) What software was already available that could be used in the data analysis?

(30) We are interested in the role of computers and software. From this point of view, how would the experiment have been different if it were done 10 years earlier? 10 years later?

Before we move on. I want to be sure what data were produced by the experiment:

(31) What kinds of raw data were created?

a) Do you think the raw data generated by this experiment would be useful to physicists outside the collaboration?

b) Where are they now?

(32) How were raw data summarized or selected? What kind of physics was being done?

a) How long are data summary tapes useful to members of the collaboration? (e.g. 5 years?)

b) Are summary data still available?

c) Could these data be used by physicists outside the collaboration? Is good software documentation still available? Where?

d) How long are DSTs useful to members of the collaboration? (estimate number of years) 
(33) We assume a formal detector log was maintained for the experiment. Where is it now?

(34) What other logbooks were kept during the experiment?

a) Was there an experiment log, or other source of centralized information used by and contributed to by all collaboration members?

If no: Where else would a collaboration member go for information on the experiment?

(35) Did you keep your own logbook on the experiment?

(36) What records did the laboratory keep?

a) Raw data tapes? DSTs? experiment logs? Progress reports?

b) Where are these?

Let's talk about writing up and communicating results of this experiment:

(37) Which members of the team reported on the physics results at international and national meetings? How was it decided at which meetings to present results?

(38) How were reports or publications drafted and circulated? Who played leading roles? Who was not involved at ali?

a) How was it decided whose name would appear on an article and in what order?

b) Who made these decisions?

c) Were people required to sign articles they did not agree with?

d) Did e veryone listed as author understand the entire experiment?

e) How was it decided in which journal to publish the results?

Looking back on the experiment as a whole: 
(39) What was the most innovative or important physics to come out of this experiment? Where was that done? IF A DISCOVERY WAS MADE, ASK: How and when did you decide to go public?

(40) Did the original goals of the experiment change in the course of the project? IF "YES", ASK: How did this affect the team?

(41) Were there secondary goals (such as engineering goals)? Which institutions were leaders on these?

(42) Were there unanticipated achievements?

(43) How would you judge the success of the experiment measured by your original expectations? Did the personnel make-up of the team or its size contribute to its success or failure? What were the principal shortcomings? How might they have been corrected?

(44) What did you do after the experiment and analysis were completed? What impact did this experiment have on your career?

Now a few questions about the accelerator site:

(45) Was there a characteristic style of this laboratory? How did your work on this experiment at this accelerator facility differ from your experiences at other facilities?

(a) Tell me about the interactions between the visiting scientists/technicians on the team and the in-house accelerator staff (physicists, engineers, administrators, and other staff).

(b) How have things changed at years?

[lab] in the past

IF THE SUBJECT WAS NOT AFFILIATED WITH A UNIVERSITY, SKIP TO QUESTION 45.

Let's talk about your home institution during the experiment:

(46) Was there any pressure from your home university as you worked on this experiment? Was there an effect on tenure, promotion, or salary decisions? 
(a) How was your teaching schedule adjusted to accommodate your participation on this experiment?

(47) Were any of your students with you at [lab]? WHETHER

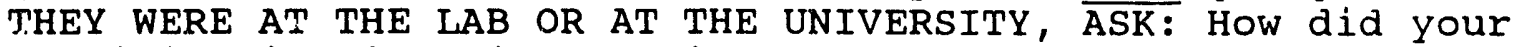
participation in this experiment affect their training? ...the training of post-docs?

(a) What was the role of undergraduates on this experiment? On campus?

At the accelerator site?

What impact did this experience have on their careers?

(48) What do you see as the major problems of graduate education in high-energy physics? Was the training of graduate students an issue of concern in this experiment?

(a) How has graduate education in physics changed since the early 1970s?

(b) How does one do a thesis when working as a junior physicist on a 100-person project that may take years to reach publishable results?

\section{A few additional questions about the team itself:}

(49) Was there a characteristic style of the team? Describe the structure for making decisions. Did these procedures change throughout the experiment? What were the rules and formalities, organizational charts, governing boards, etc.?

(a) Would you describe the team as democratic, autocratic, or what?

(50) Was there a "pecking order" within the team? Did junior people feel free to argue their viewpoints?

(51) Was there competition between this team and other groups of experimenters in high-energy physics? IF "YES", ASK: Who were they?

(a) How did the competition affect the direction and pace of this experiment? Were there any priority disputes surrounding this experiment? 
(b) Was there communication (formal or informal, iritten or oral or electronic) with competitors? ...with other collaborations?

(52) Did team members seem to get along? Were there any major disagreements or particular interpersonal problems in this experiment?

(a) Did anyone on the team suffer emotional problems?

(53) We're trying to figure out how individual contributions get recognized. Were there aspects of your contribution to the experiment which were not recognized?

(a) What personal qualities are most important for a successful career in high-energy physics?

(54) Thus far we've focussed on Experiment Now I'd like to turn to a broader subject. We would like to learn about the ways in which an experiment can be less than successful. of all the experiments you've been involved in, which was least successful? What made it so?

Finally, a last question or two about records:

(55) Were records circulated systematically? Was anyone given responsibility for keeping the documents produced by the collaboration? Who else is likely to have a fairly complete set of records for the experiment?

(a) Did the collaboration impose any requirements regarding record keeping?

(b) Which team members were good note-takers? correspondents? record-keepers?

(56) Let's estimate the volume of your records on this experiment in linear feet:

a) in office? other office? home or storage?

(57) Volume of your general records?

a) in office? other office? at home or in storage? 
(58) Do you have records on the experiment that are unique?

(59) What will happen to your files?

(60) Is there any topic you'd like to return to?

(61) Is there anything I didn't ask that you would like to talk about?

(a) What obstacles do you feel you've overcome to get this far in your career?

(b) Did the work have adverse effects on family life?

(c) Was there resentment toward those who did not contribute their share?

(62) We would like to use this interview as part of the AIP project on multi-institutional collaborations. Do we have your permission to do so? IF "YES", ASK: Do we have your permission to keep the transcript in AIP archives, after the completion of the project, for the future use of scholars?

[Using the checklist, note amount of material, approximate dates, physical condition, content, informational value, whether original or copy, and--for machine-readable records--whether the required hardware and software are still available.] 


\section{HISTORICAL ISSUES}

Interview subject

Organization within the collaboration:

for building the detector

for analyzing the data

role of spokespersons

role of lab liaison persons

Bureaucracy (formalization of social organization; operating style of the collaboration; difficulties as a result of size)

Specialization (esp. among physicists, but also the use of specialists who are not physicists)

Funding (amount; source--thru labs or direct from NSF or DOE)

Length of experiments (also length strings of experiments)

International collaboration (benefits and problems)

Detector development (types; size; built for one experiment or as a more permanent instrument)

Use of computers and software (major operational changes; develop ments by physicists; computer facilities and services at labs; off-theshelf software; sharing of software and software libraries)

Other new technologies (e.g. new plastics, new holographic technique)

Testing of the Standard Model (also the role of theory and theorists)

Styles of the national laboratories (lab administration; use of lab facilities, including engineers and technicians; other lab services, such as computer facilities; housing; patterns of lab funding)

Publications (participation in writing and revising; credits, including the order of authors and the inclusion of non-physicists; special role of Ph.D. candidates)

Graduate education (both at universities and at the labs)

Sub-contracting (or lack of it)

Use of university lab and shop facilities and staff

Communication patterns (within collaborations)

Other issues

Archives 
I. Experiment Number

II. Name , year approved

III. Position of interviewee: (Spokesperson, Group leader, other Physicist, Grad Student, Engineer, Technician ?)

IV. Employer: Current

During Experiment: .1 2)

at each institution.

Use $(\mathrm{s} / \mathrm{p})$ to indicate if student or physicist

V. Institutional archives of current employer

Name

Type

Does the institution's archives have policy regarding professional files?

yes no don't know occasionally

Does the institution's archives accept experiment files? yes no dont' know occasionally

VI. Individual has papers (general)? No

If Yes: Volume

Span dates

Location

VII. Individual has experiment files?

No If Yes: Bulk

Span dates

Location

Are experiment files copies only? no yes

Are experiment files interfiled? no yes

Specific records kept (list):

Records created but not kept:

VIIT. Other Locations of specific reocrds Name of lab where other records are: records?

Name of spokesperson having redcords Which records does spokesperson have?

other locations:

Notes: 


\section{APPENDIX F \\ Preliminary Historical Analysis of Selected Experiments}

TABLE OF CONTENTS

1. Communications $\ldots \ldots \ldots \ldots \ldots \ldots \ldots \ldots \ldots \ldots \ldots \ldots$

2. Bureaucracy and General Organization ........... 2

3. Role of spokesperson ..................... 6

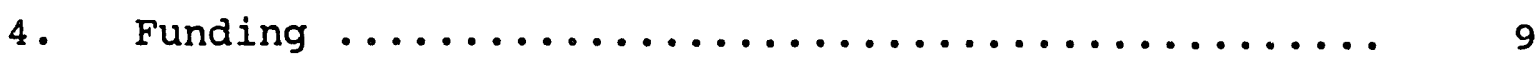

5. Experiment strings ...................... 10

6. Dissemination of Results ....................... 12

7. Graduate Education ...................... 14

8. International Collaborations ............... 16

9. Styles of the National Laboratories ............ 17 
PRELIMINARY HISTORICAL ANALYSIS

TABLE OF CONTENTS

1. Communications . . . . . . . . . . . . . . . 1

2. Bureaucracy and General Organization - . - . . . . 2

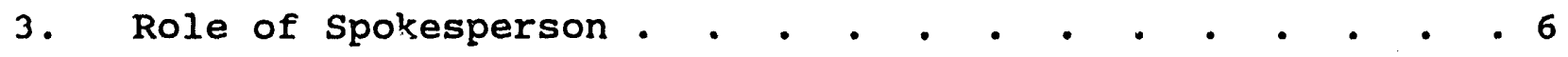

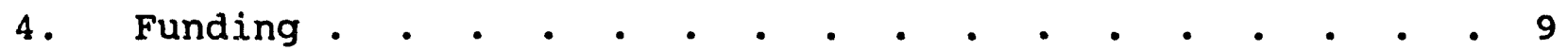

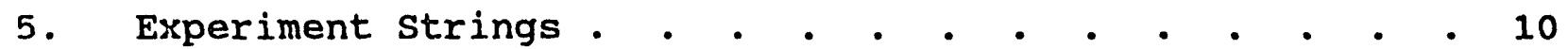

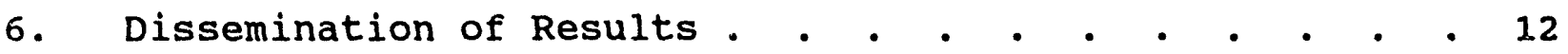

7. Graduate Education . . • . . . . • . . . . . 14

8. International Collaborations . . . . . . . . . . 16

9. Styles of the National Laboratories . . . . . . $\quad 17$ 


\section{PRELIMINARY HISTORICAL ANALYSIS BASED ON 50 INTERVIEWS}

\section{COMMUNICATIONS}

Collaborations, in attempting to keep all members adequately informed of each other's acti ities, pursue one or more of three strategies. First, one of the participating institutions, most commonly the laboratory at which the experiment is sited, may become the collaboration's de facto headquarters; unplanned encounters among resident or frequently-visiting collaborators then supplement formally scheduled meetings and written communiques to create a flow of information. Second, the collaborators may divide the labor so as to grant themselves a great deal of autonomy and independence; formally scheduled meetings then allow members to check on each other's progress and criticize each other's work. Finally, collaborations may create an information flow with numerous calls, faxes, telexes, and emails across institutional lines; meetings then become more intense and sociable versions of written or spoken exchanges.

Which strategies a collaboration can successfully pursue depend on several technical, geographical, and institutional factors. Technically, when detector components must be shoehorned together, or when a particular computer possesses superior capability for managing the data, or when the experiment is scheduled for multiple runs with time for analysis between runs, the headquarters option is typically pursued. By contrast, a headquarters is unneeded or even counter-productive when a loosely fitting detector is planned and built using university shop facilities or when film data are collected and then divided for analysis among the participating institutions. Geographically, when a collaboration is widely, especially intercontinentally, dispersed, reliance on mail, telexes, and the telephone is inescapable and a division of labor is typical. By contrast, the geographically-confined collaboration would seem over-managed if it did not make heavy use of face-to-face meetings, both formal and the chance encounter in the corridors. Institutionally, when an experiment's organizers are university faculty who must balance commitments to an experiment and their employers, or need to use the experiment to boost their standing with their employers (as in junior faculty approaching tenure reviews), a division of labor that allows them to work from their home base for much of the time seems preferred. By contrast, an experiment organized by the research staff of a laboratory usually makes the laboratory the headquarters.

How collaborations handle conflicting criteria or blend complementary options appears idiosyncratic to the individuals involved. Like everyone else, physicists are more or less willing to travel, more or less comfortable expressing themselves in conversations or letters, and more or less in need of solitude or stimulation to work effectively. However, it seems to be the case that happy collaborations cultivate a secondary

communication pattern even when one form dominates. For example, 
in happy collaborations with a headquarters, either the spokesperson has been a conscientious note-taker and memodistributor or has worked out a division of labor that delegates important work to distant institutions, because distant collaborators' trips to headquarters may not by themselves create a sufficient sense of collaboration solidarity.

viewed over time, our sample does not exhibit any clear trend, but one continuity does stand out. The collaboration meeting remains the forum for discussions that lead to decisions concerning the tactics and results of experiments. Even when physicists find meetings unpleasant -- occasionally an interviewee complains about meetings providing free rein to a long-winded colleague, the drain and expense of travel is a common lament, and personal relations are strained when collaborators who have worked independently discover at a meeting that they are in conflict -- there is a dearth of suggestions for alternatives to using collaboration meetings to debate and decide the physics issues in an experiment.

\section{BUREAUCRACY AND GENERAL ORGANIZATION}

\section{Size and Composition of Collaborations}

The organizers of experiments understand that they need to attract a vaguely-defined critical mass of people to an experiment in order to appear credible to administrators whose duty it is to assess the feasibility and desirability of a proposal. In five of seven experiments approved before 1976, organizers contacted personal acquaintances to flesh out the personnel on an experiment. In five of eight experiments approved after 1976, organizers employed impersonal means to attract people to the experiment. Apparently, collaborations have become too large for the principals routinely to know each other prior to the experiment.

organizers tend to worry simply about getting enough collaborators for an experiment rather than putting together a complementary blend of skills and sub-specialties. One organizer remembers he welcomed a university group into a collaboration because "at that time we needed to have bodies." Individual American physicists are presumed to be familiar with, if not expert in, all phases of an experimént, and any university group seems certain to encompass all the skills needed for an experiment. Physicists in all the collaborations under study have written and managed experiments' computer programs; though a few physicists are known as "computer-oriented" and specialize in working on data acquisition systems for experiments, they tend to be employed at national laboratories. Some physicists see themselves or certain of their colleagues as primarily apparatus builders or data analyzers, but everyone wants graduate students to participate in both types of work in the course of their thesis experiments. By contrast, Soviet experimentalists seem 
more sharply differentiated. One soviet interviewee reports he is labelled a physicist ir the U.K. and the U.S.A., though he is considered an engineer in the U.S.S.R. An American participant from a different U.S.-U.S.S.R. collaboration believes the soviets have created a class of people "between what we would call engineers and physicists;" these people, though not interested in the physics results, do take data shifts and therefore are included as authors for experimental papers.

Although the size of high-energy physics collaborations appears extraordinary from a historical perspective, several interviewees of varied rank have offered the thesis that experiments are systematically understaffed. One interviewee, a post-doc on the experiment being studied, recalls feeling shocked that this experiment had nearly three times as many physicists as his thesis experiment, which itself had seemed unusually large to him -- yet then found himself terribly overworked during the experiment's construction. Furthermore, the spokesperson for this experiment recalls turning away groups that expressed interest in participating. At least Iive of the collaborations in olir study added new groups after design and construction had started because more resources were found to be needed; and in one of these five, even with the extra people, the collaboration was unable to organize in advance the structure of the off-line data management. For three other experiments, which were second or higher in a string, collaborations added new groups in response to distress incurred in the previous experiment. Under-staffing does appear to have at least three advantages. First, it encourages technical, labor-saving ingenuity in fashioning and constructing apparatus; there is one case where a couple of would-be experiment organizers, in contemplating the impossibility of winning a competition with a proposal that required fewer people, reconsidered their plans, came up with a far more elegant and inexpensive design for their detector, and convinced a laboratory administration to support the experiment. Second, under-staffing promotes respect for a collaboration's division of labor because collaborators lack the resources to poach on each other's domains; generally absent from all our interviews are stories of "turf disputes" with respect to either apparatus building or data analysis. And third, understaffing inhibits collaborators from hiding or underestimating problems because nobody can afford to be unreliable in an operation on which others are working so hard; there are occasions in which collaborations have redeployed their resources in order to address areas that have turned out to be more troublesome than initially expected.

Larger experiments have led to the creation of administrative positions within collaborations: Executive committees may seek to ensure that evolving component designs do not undermine collective coherence and to reallocate resources should the development of a particular component run into snags; software coordinators may regulate changes to codes and programs used widely within a collaboration; deputy spokespersons may 
oversee construction or data runs; and ad-hoc publications committees may serve as referees between the proponents of a physics analysis and a collaboration as a whole. Issues that are the stuff of collaboration meetings in smaller collaborations are thus initially thrashed out in formalized sub-groups of larger collaborations. But even for large experiments, meetings of the entire collaboration remain the forum for making most decisions on basic strategies for designing, running, and producing results from the experiment.

One physicist, who worked on one of the smaller, early experiments in this study, left high-energy physics rather than work in ever larger collaborations. Some who have managed to keep working on smaller experiments look at the larger collaborations with a mixture of perplexity and disdain. But the people on the inside find satisfaction in large collaborations even when they had expected to feel uncomfortable. One experiment organizer, who became a physicist to avoid becoming like his father, the president of a medium-sized company, intended to create an experiment for five to ten physicists to perform but saw "the physics necessity" drive the experiment up to 40 collaborators. Still he felt "pleasantly surprised" at the manageability of the personal interactions, and succeeded in understanding and contributing to the experiment from top to bottom. He fears that he will not be pleasantly surprised again, but he is not leaving the field.

\section{Multi-Institutionality}

For many of these collaborations, neither physicists' loyalties to their home institutions nor the rules and regulations of their home institutions influence the experiments. Most collaborators accept a collaboration-wide framework as necessary to the prosecution of an experiment and tolerate inequities that may be structured into a multi-institutional collaboration. Only occasionally are there tales of physicists resisting a collaboration's structure.

When inequities in collaborations are problematic, geography seems to be the source of the inequity. If the installation or running of an experiment requires that decisions be made at a faster rate than meetings can be called, the people close to or at the laboratory will be more influential than distant collaborators. One advantageously situated physicist remembers a colleague "always screaming at me" out of frustration at his inability to influence events at a distance. one badly situated physicist seems bitter over the degree of credit that a centrally-positioned physicist and group received for an experiment that used a technique he had initially pushed. The co-spokespersons for a third experiment could not maintain a division of authority as their sabbatical schedules and job moves changed their relative accessibility to the laboratory where the experiment was to run. On the other hand, another advantageously situated physicist expresses gratitude that his distant 
colleagues recognized their limitations and helped $\mathrm{him}$ to think through the problems of managing construction. And another distant collaborator continues to work with a centrallypositioned physicist who was regularly calling meetings and preparing agendas when the distant physicist was officially spokesperson. Most physicists' comments on the geography of collaborations are not directed to the control of the experiment at all but to difficulties created for family life or teaching responsibilities by the need for frequent travel to or extended sojourns at national laboratories.

Data analysis occasionally excites a desire for

institutional independence among members of a collaboration. When the technical ability has existed for university physicists to analyze data at their home institutions - a condition that can depend on computer availability, software choices, and telecommunication links -- collaborations face a "federalist" problem: to what extent should central control of data analysis be exercised in order to ensure homogeneity of results reached at different institutions, and to what extent should local customs in data analysis be allowed to flourish in order to satisfy a wider spectrum of interests and to ensure that physics results do not depend on using a particular analysis program? At one extreme, one collaboration deliberately set up independent dataanalysis chains at different institutions and dedicated collaboration meetings to "really acrimonious" but honorably intellectual debates over the analyses. At the other extreme is a collaboration where, after two years of arguing, one contingent prevailed on the rest to give up the privilege of writing and rewriting their own analysis programs in favor of one collaboration-wide package. However, it seems more common for data analysis to be centered at the laboratory where the experiment ran and for collaborators to find a dividing line where common property and group discipline in data analysis end and where local prerogatives and individual liberty begin.

\section{Hierarchies and Social Relations}

Hierarchies obviously exist in collaborations, but nobody labels them unjust or oppressive. To one spokesperson, the tenured faculty in a collaboration are the truly responsible parties for an experiment, since all others are in principle transitory. Tenured faculty represent the collaboration to outsiders, especially review panels. For internal affairs, the interviewees mostly remember their collaborations as "democratic" in discussions of experimental strategies and data interpretation and "consensual" in decision-making. Inevitably, high-ranking collaborators will feel the need to make some decisions before the next collaboration meeting can be convened, and uncoordinated, disagreeing leaders can create grief for the lower ranks. However, most major physics decisions, such as the energy at which to set the beam for a data run in a collider experiment or the suitability of a result for publication, are made at 
collaboration meetings where everyone of all ranks is able to participate on an equal footing.

Rank sometimes comes to the fore when schedules for staffing data-run shifts are worked out. An unwritten rule of one collaboration, according to a graduate student, was that the students whose dissertations depended on the data being collected would put a disproportionate amount of time into staffing the data runs while more senior people commuted to the laboratory. That apparent imposition is a double-edged sword. Most interviewees who have commented on the subject say that students and post-docs at the lab quickly outstrip faculty in their understanding of and skill at manipulating the apparatus and software; the faculty can then get their way with the students only through persuasion. Thus the graduate student's drudgery can quickly make him a group leader's intellectual equal.

When full-time at the laboratory, graduate students seem to

have the most contact with the laboratory's engineers and technicians. In the only experiment thus far on which there are interviews with engineers and technicians, mutual appreciation was the order of the day (at least as far as the laboratory staff was concerned). The staff professed to be comfortable dealing with senior physicists in informal or laboratory settings; however, collaboration meetings seemed at best a waste of time and at worst an occasion where the physicists would "put you on the hot seat and make you miserable." Therefore, the staff appreciated the students' willingness to explain the experiment's physics and to keep the staff posted on what happened in collaboration meetings. In return, the staff would teach graduate students "nands-on" science. When the academic demand for high-energy physics doctorands was slack, as one engineer believes was the case during this experiment, this experience in more technical areas could prove vocationally valuable.

\section{ROLE OF SPOKESPERSON}

To be spokesperson, one practitioner observes, is both cherished as a symbol of scientific initiative and despised for the administrative tasks that come with it. While not all physicists dislike serving as administrators, collaborations in the later period covered in this study do appear to be generating more managerial tasks, and the meaning of being spokesperson and the role the spokesperson plays seem to be in flux.

In the nine experiments approved in or before 1975, the spokesperson has boen either the intellectual initiator of the experiment or, in those experiments that were second or higher in a string, a physicist dedicated to the program and deserving of sharing in "the burdens and the glory" that come with the title. The spokesperson would be responsible for making presentations to the laboratory administration and then chairing collaboration meetings. But except when the assembly of the detector at the laboratory was tricky or laborious (in which case the 
spokesperson oversaw the on-site construction), these experiments rarely generated organizational issues that made the spokesperson seem particularly critical in his own or his collaborators' eyes. The spokesperson for one of these experiments said nothing in his interview about being spokesperson, and a non-spokesperson interviewed for a different experiment could not recall who the spokesperson was. Others spoke of "collective decision-making" or "pure democracy" as the appropriate form of governance. When hierarchies based on professional rank were evident to the participants, the spokesperson "had no particular role" beyond that of other group leaders. For only one experiment did an interviewee complain that the spokesperson did not provide an adequate managerial and communication structure for the collaboration. In one other experiment a group leader retrospectively wished he had insisted on being co-spokesperson; the source of his regret appears not to reside in how the experiment was executed but over the lack of recognition he and his institutional colleagues received relative to the spokesperson and his colleagues.

The eleven experiments approved in or after 1977 contain a variety of managerial practices not found in the earlier collaborations. In seven of these experiments, some sort of administrative sub-structure, such as deputy spokespersons, executive committees, or ad-hoc committees, were formed to handle collaboration business. In two of these seven, collaborators insisted on the additional administrative structures out of frustration with the inability of spokespersons, who held their positions by virtue of being among the experiments' initiators, to manage the collaboration's affairs. No such stories have yet appeared for the other five. But in three of these five, the spokesperson has shifted more than once over the course of the experiment, and in one of these three the spokesperson is formally elected annually by the collaboration at large; in another of these five, the collaboration "informally elected" as spokesperson the physicist best positioned to deal with the laboratory, and that person passed on the office when his change of job eliminated that qualification. Only one of these seven experiments had both a long-term spokesperson who was an intellectual initiator and an administrative sub-structure that was not imposed from below.

Even among the four experiments with neither sub-structures nor shifting spokespersons, in two there are signs of administrative burdens that neither the spokesperson nor the collaboration as a whole handled well. In one, which a collaborator described as "autocratic and well organized," the spokesperson still delegated responsibility for laboratory relations to a junior faculty member of his university. In the other, where the spokespersons exercised little authority beyond chairing the collaboration meetings, papers were drafted and submitted to journals without undergoing collaboration-wide review. The other two experiments, which most resemble the pre- 
1976 experiments, were both parts of strings that dated back to that period.

The need to strengthen collaborations' managements is certainly to be expected as the drive to produce more refined, sophisticated measurements requires larger, more complex detectors which absorb the design, construction, and analysis efforts of more physicists. In most of the more recent experiments, neither the individual spokesperson nor the collaboration as a whole can coordinate and evaluate the many tasks of the collaboration's members. Thus they create: the executive committees that seek to ensure that evolving component designs do not undermine collective coherence and to reallocate resources should the development of a particular component run into snags; the software coordinators who regulate changes to codes and programs used widely within the collaborations; the deputy spokespersons who oversee construction or data runs; and the ad-hoc publications committees that serve as referees between the proponents of a physics analysis and the collaboration as a whole. And thus even experiments that do not create substructures show signs of needing them: as when an autocratic spokesperson delegates authority to a junior colleague; and when a loosely run collaboration loses track of the status of its individual members' projects.

The practices of shifting spokespersons, selecting them for their administrative skills or position, and occasionally insisting from below on extra administration also suggest that the characteristics of some experiments and collaborations require that managerial skills be placed ahead of intellectual initiative as the defining character of spokespersons. Shifts of spokespersons or discontent with a spokesperson's performance are more common for collider experiments and experiments that collect data on film than for fixed-target, electronic experiments. The former seem to contain more possibilities for experiments within experiments because collisions seem subject to fewer controls or the detector cannot be so readily adjusted to restrict the kinds of data it collects. When an experimental set-up can be used for several physics projects, collaborations seem to be coalitions that need managers who can work out agreements on what physics gets done, who does it, and when it can get done. There seems little role for enduring leadership in such a collaboration, and shifting the burden of managing such intrinsically divisive issues may keep resentments towards any individual from accumulating.

Even in a recent fixed-target, electronic experiment whose set-up does not seem to differentiate collaborators on the basis of their physics interests, the use of intellectual initiators as spokespersons has proved problematic. This collaboration named as co-spokespersons two junior faculty who had contributed heavily to the experiment's design and justification because the credit thus conferred was assumed to help them win tenure from their home universities. The result was a series of administrative tangles as each "displayed remarkable talent for 
messing in each other's front yard" in his efforts to put his personal stamp on the experiment. By contrast, a fixed-target experiment that chose as spokesperson the physicist best positioned to deal with the laboratory did not generate such tensions. Insofar as collaborations grow larger and the frequency with which they include several junior faculty increases, pressure should increase to break the association between appointment as spokesperson and scientific leadership.

\section{FUNDING}

Each high-energy physics group in a U.S. university maintains an ongoing contract with either DOE or NSF. These university groups, whether funded by DOE or NSF, appear to vary in the extent to which they function as groups; some seem little more than holding companies for their individual members who independently join or start experiments, while others decide collectively what experiments to join. Further generalizations would require university - and agency-centered studies in contrast to this experiment-centered study.

The interviews so far analyzed have revealed little about who, if anyone, computes an experiment-wide budget, who in a collaboration can authorize expenditures, and how funds are tracked through an experiment's duration. It does appear that the politics of acquiring funds from DOE or NSF are simplest when the experimenters make use of equipment already developed or when the laboratory that approves the experiment has the money and discretion to pay for the materials and manufacturing help the experimenters must buy. Then the university contracts with the agencies need only cover salaries and travel expenses. Matters become more complex when collaborations must fund construction through university contracts, especially if both DOE and NSF institutions are involvet. Then the principal investigators must "make the rounds" of the agencies and broker an agreement for who will pay for what. During the remainder of the study, we should try to learn what university physicists feel will routinely be covered in their ongoing contracts and what requires substantial justification.

In one case, an eager collaborator, whose experiment had received laboratory approval but who still needed to obtain agency commitments, solicited and received permission from his university's administration to start spending money. This permission was effectively an unsecured loan made on the assumption that government funds would indeed be forthcoming. They were -- otherwise this experiment would not have existed for us to analyze -- but one wonders whether anyone has had this strategy backfire and what the consequences have been.

Because of the ruble's dubious value, the physicists in a U.S.-U.S.S.R. collaboration worked out their respective contributions through barter. This agreement was apparently trouble-free. 


\section{EXPERIMENT STRINGS, DETECTOR DEVELOPMENT, NEW TECHNOLOGIES AND SUBCONTRACTING}

of the 20 experiments on which data are now available, 12 were classified by interviewees as the second or higher in a string of experiments, and another four generated at least proposals for a further experiment. Only four experiments were freestanding. The obvious (and unsurprising) implication is that physicists build their research programs within a body of techniques that changes sufficiently slowly to allow a strong sense of continuity across experiments. Strings are generated by winning approval to run a variation in some element(s) of a previous experiment -- either the beam, the target, the detector, or the physics examined -- and for the most part, variations in apparatus are produced with only routine help from industrial firms. Characterizing the enduring and evolving elements in experiments will be a challenge for future historians and sociologists.

The most common strategy for strings of experiments (11 of 16) is to hold constant the beam and target while varying the detector. Experimentalists justify the value of detector variations by claiming the improved detector will do a better job of examining the subject of the previous experiment, or will enable the examination of subjects that the previous experiment had not (or could not possibly have) planned for. The second justification is more common ( 6 of 11) and probably more successful than the first, because it is difficult to produce a sufficiently improved detector at a sufficiently modest cost to reexamine a topic except when the previous experiment had turned up evidence for a novel process. (In three of the four experiments that were approved to reexamine their predecessors' physics, the processes involved were novel.) Indeed, within a string, experimenters most frequently improve a detector ( 6 of 11) by adding components to the extant detector in order to expand its range; only occasionally do they seek to improve the performance and resolution of individual components. In only two of these 11 cases did physicists tap industrial expertise to address technical problems (once with success, once with failure). While virtually all collaborations contract out such mundane tasks as stuffing circuit boards that physicists have designed, in none of these 11 experiments did detector improvements stem from commissioned attempts to advance industrial practice.

Five of the sixteen string experiments were not generated by varying the detector. Four of these five were fixed-target experiments that did not employ a secondary beam. Two collaborations generated strings by varying the material used in the target, while one used an accelerator's planned improvements to expose the same target to different energies. Only one experiment was based on cultivating an ability to inject "boutique" particles into the accelerator in order to customize 
the primary beam; the rarity of this strategy is probably due to the delays and difficulties such practices cause a laboratory's other experiments. The fifth experiment inaugurated a new detector, developed at a national laboratory, which could be used by users in experiments designed with or without the laboratory's participation. The last two of these experiments presented technological challenges. In one, industrial help was unsuccessfully solicited, but the experimenters found a way around the problem independently; the other was worked out entirely by the experimenters without apparently approaching industrial firms.

Two factors seem to contribute to making an experiment freestanding. First, the collaboration proposes a novel detector or a novel detection strategy for the accelerator, so that the experiment seems unprecedented to its practitioners, even if they have worked together previously. One would expect the desire for technical novelty to drive experimenters into close relations with industrial firms, and for at least two of these experiments, industrial firms were commissioned to help design apparatus or to produce needed materials of suitable quality. Second, the experiment ends without anyone proposing a continuation because either the novel element does not perform well enough to seem worth pursuing ( 1 of 4 ) or because the collaboration is able to internalize the basic art of the string -- that is, elaborating on a detector to address a variety of physics issues that are embedded in a particular combination of beam and target -without formally proposing a new experiment. Collider experiments seem especially well suited to internalizing the art of the string; three of the four freestanding experiments are collider experiments while only one of the twelve string experiments are. Collisions generate multiple processes deemed worthy of study, and experimenters surround the collision points with detectors that can reconstruct several types of events. Thus the collider experimenters can shift their focus without building new components (and submitting a new proposal to raise new capital). In the most extreme case, one experiment monopolizes a collider, even though there is a second interaction zone, because any further detection capabilities would be redundant. "Upgrades" rather than "strings" may become more meaningful as a term for describing what a collider collaboration desires should it submit a new proposal to a laboratory's administration.

A final striking correlation is that all four freestanding experiments are international collaborations while only four of the sixteen actual or would-be strings have institutions collaborating from outside North America. (Two others had Europeans participating on an individual basis.) It is unclear whether there is something about the freestanding experiments that make the problems of international collaborations more easily borne or whether they coincide with other forces that encourage international collaborations. 


\section{DISSEMINATION OF RESULTS}

Interviewees for six experiments from the early period of this study make little or no mention of talks at meetings and conferences. For the rest, talks are an important, though not always rare, commodity that a collaboration exercises care in distributing. Talks are invariably considered valuable for bringing results quickly to the wider community's attention, although collaborations vary in whether they review talks as rigorously as they do proposed journal articles. Talks are invariably considered valuable for conferring credit and granting exposure to the collaboration's lesser-known members who have driven forward a particular line of analysis, although who chooses the deserving individual varies across collaborations. The question set is not designed to elicit the standards that collaborations set for conference talks, but some variations in opinion are apparent. Two collaborations imposed less stringent standards on talks than on publications: in one, "a result that you think is right within reason" could be presented at a conference, while journal articles had to be as trustworthy as possible for future physicists; in the other, laboratory seminars were used to try out questionable results or ideas. By contrast, interviewees from three experiments report that the collaborations rigorously reviewed the content of at least some talks; in one case, a collaboration waited several months to present a central result to the accelerator laboratory's seminar while they worked at making the result as convincing as possible, even though the collaborators felt certain about the result. such discipline proves difficult to enforce pleasantly. one of the collaborations suffered from "bad citizens giving impromptu talks" while in another "a bit of feeling" was aroused when one collaborator blocked another from giving a seminar at an accelerator lab.

Most collaborations do not use collaboration meetings to decide who speaks at conferences, except when choosing someone to present important results at major conferences -- in which case the presenter's reputation and speaking abilities as well as his contribution to the results are taken into account. There are a variety of other ways for making such decisions. In two collaborations, the spokesperson either openly or effectively decides; more commonly, the group leaders will collectively make the decision; when institutional lines remain meaningful through the course of an experiment, the collaboration may grant talks to member institutions rather than individuals with each group responsible for deciding who will speak. Two collaborations did collectively decide on conference speakers: in one, the responsibility for analyses was well enough defined that there was rarely any issue over who should present results; in the other, most collaborators were concerned with one central topic, and collaboration-wide discussion insured equity and curbed "a few individuals who like to give all the talks." In general, 
where disputes over who gives presentations is occasion, it seems collaborations delegate responsibility for making those decisions, but where such disputes are either rare or frequent, collaborations collectively make those decisions.

For the production of journal articles, the power of writing the first draft was inconsequential in the overwhelming majority of experiments. In only one instance, where the experiment's leaders felt themselves to be in a race to claim a discovery, did anyone report that the mass of collaboration members were denied the opportunity to criticize an initial draft. For the experiments approved before 1976, there were no formal intermediaries between a paper's drafter and the collaboration as a whole. But in six of eleven experiments approved since 1976, collaborations have created committees to work with paper drafters before or after the collaboration as a whole has discussed the results. As collaborations have grown larger and more geographically far-flung, there are obvious economies in minimizing the number of times a collaboration meets to discuss the merits of a particular proposed publication. However, thus far we see no neat criteria for distinguishing the collaborations that have and have not instituted such procedures.

Interviewees have reported instances where papers have sailed through with one set of revisions, and instances where the collaboration insists that the initial drafters start again from scratch. The general ethos, which has remained constant over time, is that consensus within the collaboration should be reached before a paper is submitted to a journal, with a paper's detractors subject to the constraint that "you can't be the only one, and if you are, you better not be it each time." There are no reports of individuals in the experiments under study asking to be removed from author lists out of distrust of a paper's results; indeed, one interviewee recalls that the collaboration averaged the results of differing, independently-produced analyses rather than either putting off publication or publishing separate papers. (There are, however, reports of people taking their names off papers from other experiments not in our sample.) In experiments that effectively contain experiments within experiments, collaborators are known to remove their names from author lists from a sense of not having contributed to the results; such actions may indicate their belief that the result was not worth the effort to produce it.

At least five of the collaborations examined have tried to recognize an individual's contributions to a particular ana'vis by placing him at the head of the author list. Discussion: $f$ who belong in that position, to an even greater extent than who deserves to present a paper at a conference, generate "more heat than light." A veteran of such discussions recommends that they be scheduled for just before lunch or dinner, when everyone is eager to adjourn. One collaboration that stuck to recognizing individuals with first place on an author list decided that the results of two independently-written doctoral theses should be included in one article; the ensuing debate over who should be 
listed first was "the most acrimonious" in a collaboration notable for a high degree of internal competition and fierce debates over data interpretation. Those collaborations that use an alphabetized author list do not have such headaches, and one spokesperson actually prefers alphabetized lists because they drive home the point that "there's more to doing an experiment than doing a particular analysis." Besides occasionally stressing first place on an author list, collaborations try to maintain the significance of the author list by resisting the temptation to include engineers on experimental papers or through rules that limit how long a physicist can remain an author after he leaves the collaboration. (Those same rules may also protect physicists who leave an experiment before significant data come in from losing credit for their efforts to design and build the experiment.) However, the overwhelming impression given by the interviews so far analyzed is that reputations in high-energy physics are built through word-of-mouth, letters of recommendation, and participation in conferences rather than from formal publication credit.

For two-thirds of those collaborations whose members expressed an opinion, physical Review Letters was and remains the journal of choice. But a distinct minority preferred or has come to prefer physics Letters, because it turns around manuscripts more quickly and is more flexible on issues of article length.

\section{GRADUATE EDUCATION PLUS LENGTH OF EXPERIMENTS}

The ideal experience for a graduate student in high-energy physics is to become involved with an experiment as it is being planned, write a thesis that analyzes data that the experiment produced, and emerge familiar with all phases of a high-energy physics experiment. Interviewees recall pre-1980 experiments as reasonably conducive to that ideal; rather than finding themselves little fish in a big pond, the students benefitted from being involved in a broad, yet intellectually manageable, range of subjects and techniques. No interviewee for a more recent experiment has said outright that the experiment proved a bad vehicle for graduate education. But many faculty worry that their next experiment will be the one whose length and complexity force their students to spend too much time on too few subjects, and some have begun wondering how such changes in experiments will affect the personal qualities students need to succeed in this field.

Long, complex experiments pose two types of dangers for graduate education. The first is that the time from planning to data runs will exceed the norms for duration of a Ph.D. program, so that students will no longer be able both to construct apparatus and to analyze data from an experiment. In one of the experiments being studied, some students had to wait for data to analyze because the novel detector took longer to build and debug than expected; in another experiment that assumed technical 
risks, a university collaborator directed graduate students towards other projects that seemed more certain of generating material for dissertations. Several faculty forecast that universities will have to award degrees for theses that deal solely with instrumentation. (It is apparently unproblematic to justify theses that deal solely with data analysis.) such students would either have to round out their educations as postdocs or build careers as hardware specialists. Others recommend that students earn degrees by analyzing data from an experiment that is already running while building apparatus for an experiment that will run after they get their degrees, though it is easier to analyze data from a detector one knows from the inside and to lavish craftsmanship on a component that will collect data the builder plans to analyze.

The second danger to graduate students is that the experiment will take data over several runs, and the student who has become expert on particular parts of the detector will become too absorbed in making the experiment run smoothly. For example, one interviewee reports that one of his students, in a recent experiment not included in our sample, became so adept at managing runs that he became shift supervisor and "spent so much time making the apparatus work and making programs work that he didn't spend as much time studying the physics." Another prefers to preempt this possibility by having students return to campus once they have enough data from which to write a thesis. Such an arrangement is of course possible only when a collaboration manages its data and software so that analyses can be done on campus. The arrangement carries potentially profound, difficultto-predict implications for the student's development: the oncampus thesis writer has the opportunity to audit courses and attend colloquia that may broaden his education, while the laboratory-based writer can constantly talk shop and make contacts with high-energy experimentalists on his own and other experiments.

To be a success in high-energy physics, in the opinion of some interviewees, requires that students possess more than conventional scientific talent. One physicist, contemplating the uncertainties in mounting experiments, thinks students must make "political judgements" about which experiments will get beam time and data and that the politically savvy student will have the advantage. Another, contemplating the ease with which a student can cultivate a technical expertise that will let him float from experiment to experiment, worries that the field is attracting students more interested in the technology than the physics of experiments. The students with ambitions to become scientific leaders, he fears, will have to be "little sharks" in order to gain the resources to have a visible impact on an experiment. 


\section{INTERNATIONAL COLLABORATIONS}

International collaborations appear to be children of necessity. From the perspective of U.S. experimentalists (which is the perspective of most interviewees in our sample) any of four factors behoove experimentalists to seek foreign collaborators. First, a foreign group has developed an experimental technique that U.S. physicists wish to use and learn. Second, an experiment requires more manpower and money than can be readily raised domestically. Third, a laboratory director recommends that the proposers of an experiment join forces with foreigners with similar interests. or fourth, U.S. experimenters with a working detector desire more beam time than a U.S. accelerator has the willingness or ability to provide. For the non-American experimentalists, collaborating with Americans is a means for performing experiments for which appropriate equipment is locally unavailable.

Four kinds of problems, beyond obvious ones such as language, appear in international collaborations: technical, political-legal, logistical, and cultural. Technical problems, stemming from the use of different metrics and standards in various nations, are well within the power of physicists to solve, and there are no examples of such problems not being routinely dispatched. The potential for political-legal problems has been most worrisome to American-soviet collaborations, though one West European physicist reguired a laboratory director's help to get his visa extended when the experiment took longer than planned; in one American-Soviet collaboration, the physicists "conspired together to fight each other's [governmental] bureaucracies," and even managed to survive a Soviet's defection. Logistically, coordination of international collaborations is difficult because of the expense and drain of travel for meetings; furthermore, before computers were networked together, either foreign physicists gave up trying to analyze data from their home institutions (because by the time they had installed the software on their institution's computer, the programs had been changed) or the collaboration struggled to pull consistent results out of analyses performed with different codes on data of different vintage. Culturally, American physicists have confused Japanese with vociferous arguments that do not indicate personal antagonisms while Americans have been disoriented by Japanese processes for reaching consensus or differentiating open-ended projects from delimited tasks. Europeans and Americans have brought to collaborations contrasting assumptions over the degree to which collaboration-wide rules, especially for handling raw data and reconstructing events, should be instituted over the autonomy of the participating institutions, with the Europeans accustomed to a more centralized framework.

Despite the difficulties of working out such problems, almost all participants in international collaborations found that the pleasure of building new personal relationships with foreign physicists more than outweighed the difficulties. Time 
and experience should erode cultural misunderstandings, and further innovations in communication and transportation may alleviate logistical burdens. But as experiments grow larger, longer, and more expensive, legal impediments to long-term residencies by foreign nationals can only grow more threatening. Not only will physicists need visas, their spouses will likely want the right to pursue their careers during a long stay in the U.S.

\section{STYLES OF THE NATIONAL LABORATORIES}

The comments of interviewees about the national laboratories cluster around four topics: the laboratories' technical capabilities and the responsiveness of their technical staffs, the character of interactions with the laboratory's administration, the quality of extra-work life around the laboratories, and the strength and power of the laboratories' inhouse research groups. Nearly every laboratory user had complaints about the laboratory at which his experiment was run. Laboratory staff members, not surprisingly, are more tolerant or defensive about their laboratory's character.

The ability of experimenters to work harmoniously with the accelerator division and other divisions of a laboratory's staff is generally important for happy experiments, and particularly important when some unique feature or potential in a laboratory's beam makes that laboratory the preferred site for the experiment. Virtually all users concur that relations with a laboratory's staff are facilitated by having physicists from the laboratory's research division in the collaboration; therefore, universitybased initiators of experiments have consciously searched for laboratory collaborators. Still, in this sample there are examples of experiments performed at Brookhaven and SLAC without laboratory collaborators; Brookhaven users in this situation tend to complain about the quality of services they received while SLAC users tend to complain about the quantity of services they received. Most Fermilab experimenters -- especially those who have done experiments at CERN, the apparent leader in providing quantity and quality of services to experimenters -- feel they have to take care of more matters on their own.

Laboratory directors and Program Advisory Committees do not receive much criticism in these interviews. The conditions that they insist that experimenters satisfy are rarely the object of controversy (though everyone we interviewed talked about proposals that were accepted and experiments that ran rather than ones that were not or did not). There is only one instance reported of a laboratory director telling an experimenter how to build an experiment; and the interviewee, a longstanding member of a laboratory's research division, ignored the director and on no other occasion received such advice. Occasionally, experimenters complain that laboratory administrators adhere too strictly to their policies. For example, one experimenter felt 
that his collaboration was forced to announce a provocative result in order to lay a public foundation for requesting more beam time, when he would have rather struck a discrete deal for more time and double-checked the result before making any announcement. Most commonly, experimenters express regrets that a laboratory administration's decision to dedicate resources to a new or upgrading accelerator affects extant facilities and running experiments.

The isolation of Fermilab and Brookhaven from cosmopolitan amenities wears especially on unmarried physicists who crave a social life, but SLAC is frequently criticized for not providing enough help with visitors' housing, dining, and transportation needs. Cornell, whose collider is drawing increasing interest while SLAC struggles to bring a new collider on line, will probably become the object of similar complaints. CERN appears to be the most pleasant laboratory for a visitor to live near for extended periods.

SLAC is invariably considered to have the most intellectually and institutionally powerful in-house research groups. Three contrasting explanations have been offered for the strength of SLAC's in-house groups: one non-SLAC physicist believes that lack of widespread interest in SLAC at the time of its origin forced SLAC to cultivate strong in-house groups; a SLAC faculty member suggests that the intrinsically high backgrounds in electron experiments, and the consequent complexity of the detectors need to collect results, required that in-house groups be cultivated for detector development; another SLAC faculty member suggests that the proximity and relationship between SLAC and stanford somehow leads to strong in-house groups. SLAC faculty acknowledge that the strength of SLAC's in-house groups usually behoove outsiders to hook up with an internal group. SLAC faculty justify their power by arguing that experiments are better run by people who can dedicate themselves full-time to the experiment and that complaining users are fundamentally distressed at their inability to be full-time experiment directors at an off-campus laboratory while discharging their on-campus responsibilities. 
APPENDIX G

\section{Preliminary Report on the Upsilon Probe}

These preliminary findings are based both on interviews conducted with participants and on records located at Fermilab, CERN, and a number of universities. All but about 10 of the planned 60 interviews for this probe have been conducted, though the analysis of these interviews is at a preliminary stage. The probe study seems to corroborate most of the conclusions reached through analysis of the other interviews and to suggest other conclusions.

In the Upsilon experiments, collaboration meetings were, by all accounts, productive sessions, though a good deal of discussion was carried out by means of memos. The size of the collaboration increased markedly from 1970 until the mid 1980s. Despite the fact the last experiment in this string, E-605, was the largest, it seems to have been the most winderstaffed, particular$1 y$ in its final stages and with respect to graduate students and post-docs. As a result, data analysis has taken longer than expected, and a good part of the data from the 1985 run has still not reached publication.

E-605 was an international collaboration, involving a large Japanese team and two European teams, but data analysis took place largely at Fermilab, so the geographic spread of the collaborators did not cause major problems. Those interviewed were in agreement that Europeans fit easily into the American setting--apart from their annoyance at certain lab practices--but that most of the Japanese remained rather aloof from the rest of the collaboration.

Respondents were in agreement that decisions were reached almost always by consensus and usually at collaboration meetings. Lederman appears to have been a very strong leader, though very informal and not at all authoritarian in his style. It was his assiduous work on and detailed understanding of almost all 
aspects of the experiments, together with a physics insight that by all accounts was extraordinarily good, that made him an effective leader. Also extremely valuable to the collaboration were Lederman's personal connections with physicists worldwide. study of the Upsilon experiments makes clear that a string of experiments is sometimes a better unit for historical analysis than a single experiment. This is because experiments--even when directed toward different physics questions--may be very closely related. Part of the relatedness is in continuities, such as in personnel or detector design. Experiments can be related in other ways, such as when the results of one search prompt a different search or when the experimenters turn from a search for resonances to precise measurements of them. The experiments studied in this probe display many types of continuity as well as other sorts of relatedness. The most important continuities were in individual and institutional participation, in hardware and software design, in physics questions, and in the setting for the experiments.

Historians of science have often traced the evolution of a scientific theory and occasionally the evolution of a scientific instrument. Study of the Upsilon experiments shows that understanding of experimentation in high-energy physics requires a consideration of how experimental apparatuses evolve. There was a continuous evolution of detector design from the detector of E70 (a single-arm spectrometer) to the detector of E-605 (a much larger double-arm spectrometer). An apparatus is a complex of different hardware components, including magnets, absorbers and shielding, chambers for tracking particles, calorimeters for recording energy deposited by particles, electronic circuitry to transfer data or to trigger the recording of data, and various computer hardware and software. The parts of a detector are often re-used, both in detectors later built by the same collaboration and in detectors built by others. For example, parts of the E-70 spectrometer were used in building the E-288 spectrometer, and some wire chambers built for a Brookhaven experiment 
directed by Sam Ting were used in E-288. A huge magnet used in E-605 was built from the cyclotron at Columbia University's Nevis Lab. The computer programs used in one experiment were frequently re-used, though usually in a considerably modified form, in later experiments. Moreover, even when detectors are almost entirely rebuilt, there may be a great deal of continuity in detector design; E-605 provides an example.

Study of the 20-year course of the Upsilon experiments revealed several examples of how one experiment can spawn a subsidiary experiment or "subexperiment", sometimes because someone realizes that the apparatus built for one purpose can, with little modification, be used for another or because one result suggests a different search or measurement. The subexperiment may or may not be assigned a new number. An example of the former possibility is E-608, which was a very short experiment making use of the E-288 apparatus. An example of the latter possibility is the search for phi mesons, which was regarded as part of $\mathrm{E}-70$.

The Upsilon experiments illustrate the dangers of caution and of boldness in announcing experimental findings. Lederman did an experiment at Brookhaven in the late 1960 s which found a bump in the graph of the masses of virtual photons created in hadron collisions. Lederman remarked on the "shoulder" in the graph but did not claim it as a resonance or particle. In 1974 work by Ting at Brookhaven and Richter at SLAC showed that "Leon's shoulder" was a new long-lived particle (now called the $\mathrm{J} / \mathrm{psi}$ ). At that time Lederman's group at Fermilab was still taking data with the single-arm spectrometer $(E-70)$; had they gone earlier to the double-arm spectrometer (E-288, originally Phase 2 of E-70), as was planned, they could have been the first to see the J/psi. Having missed out there, Lederman's group was probably less cautious than they would otherwise have been in announcing the detection of a resonance at $6 \mathrm{GeV}$ in January 1976, which they named the Upsilon. They soon found that this apparent signal was merely a statistical fluctuation (and now called the 
"oops Leon" particle). Then about one year later this group found an apparent resonance at $9.5 \mathrm{GeV}$. This time they amassed abundant data before announcing the result.

The Upsilon probe also shows clearly how important experiments are in the training of physicists, both at the predoctoral and postdoctoral levels. Participation in an experiment usually involves work in detector design, detector construction, datataking, software design and debugging, and data analysis. Many of the skills needed by experimental physicists are not taught in courses, so on-the-job training is the norm. By being a post-doc on an experiment, a physicist adds to his experience in the areas mentioned above and acquires management skills. Pre-doctoral students gain experience and the material for a Ph.D. dissertation. From the Upsilon experiments came 18 doctoral dissertations (and these dissertations, we have learned, provide the best documentation of many aspects of the experiments). On the other side of the ledger, most experiments depend upon the labor of grad students and post-docs. The lengthened course of an experiment has made it more difficult for a grad student or a post-doc (who has, in many cases, only a two- or three-year fellowship) to take part in all the phases of an experiment. This difficulty was seen in E-605. It appears that this experiment was in the later years (the experiment was approved in 1979, data-taking ended in 1985, and data analysis is still being done) understaffed in post-docs. Grad students on E-605 had then a greater burden of data analysis and took longer to complete their degrees.

July 1990

Frederik Nebeker 


\author{
APPENDIX H \\ Four Issues of the AIP Center Newsletter
}

May 1988: "Center will Study Scientific Collaborations," pp. 1,4 .

May 1989: "New Grants Support Documentation Work Outside the U.S.," pp. 1-2.

Fall 1989: "First steps in AIP study of Collaborations in High-Energy Physics," pp. 1-2.

Fall 1990: "Progress on AIP Study of Research Collaborations," pp. 1-2; and "Preliminary Findings of AIP High-Energy Physics study," pp. 4-5.

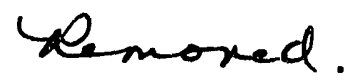



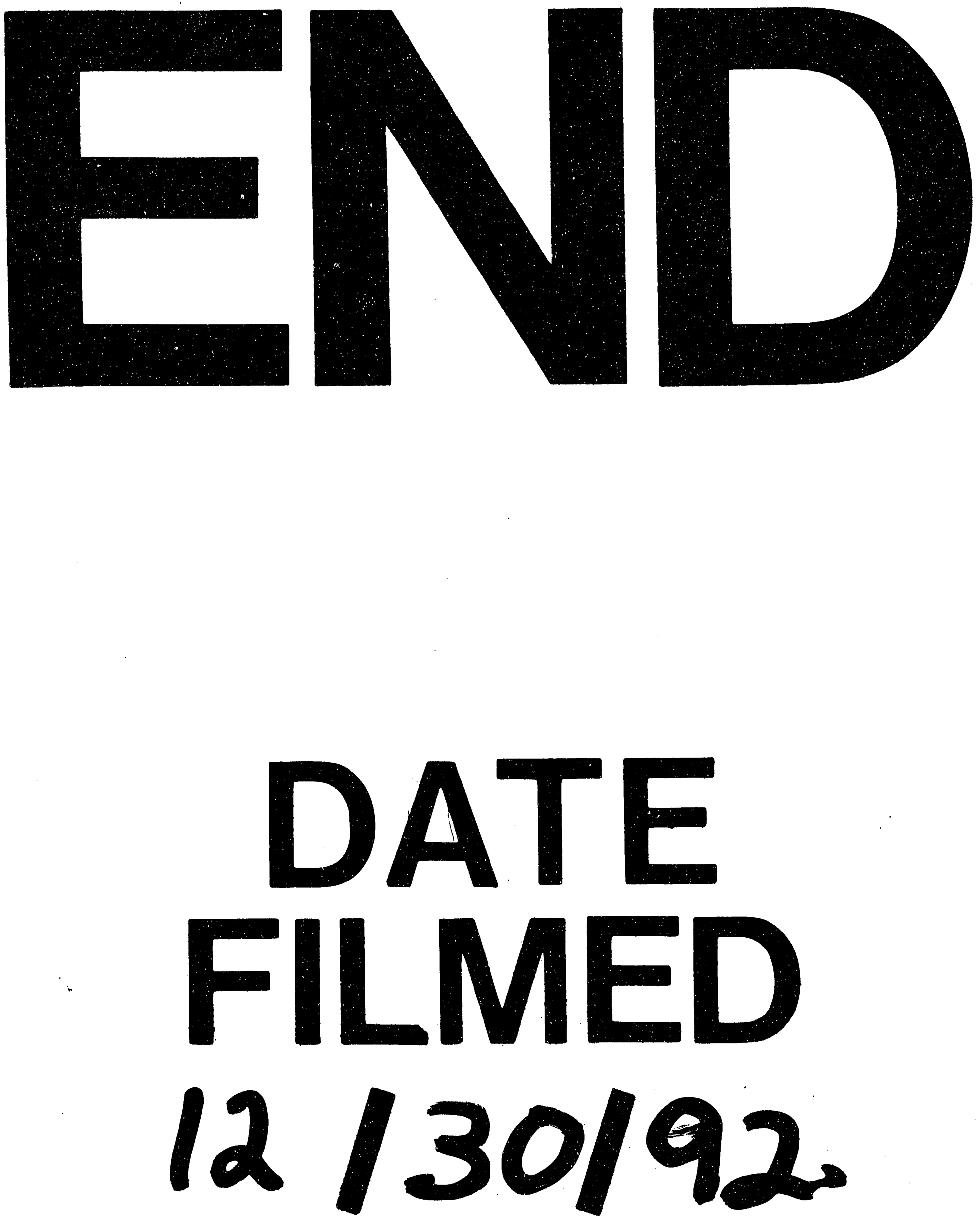
